
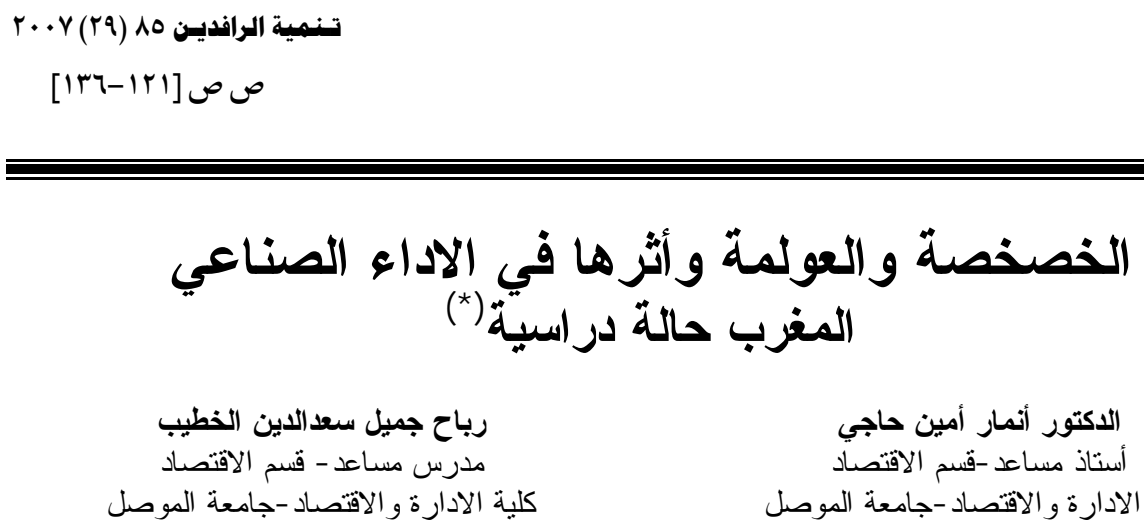

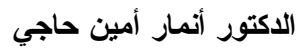

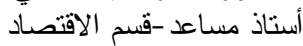
كلية الادارة و الاقتصاد -جامعة الموصل
Anmar_1961@yahoo.com

كلية الادارة و الاقتصاد -جامعة الموصل

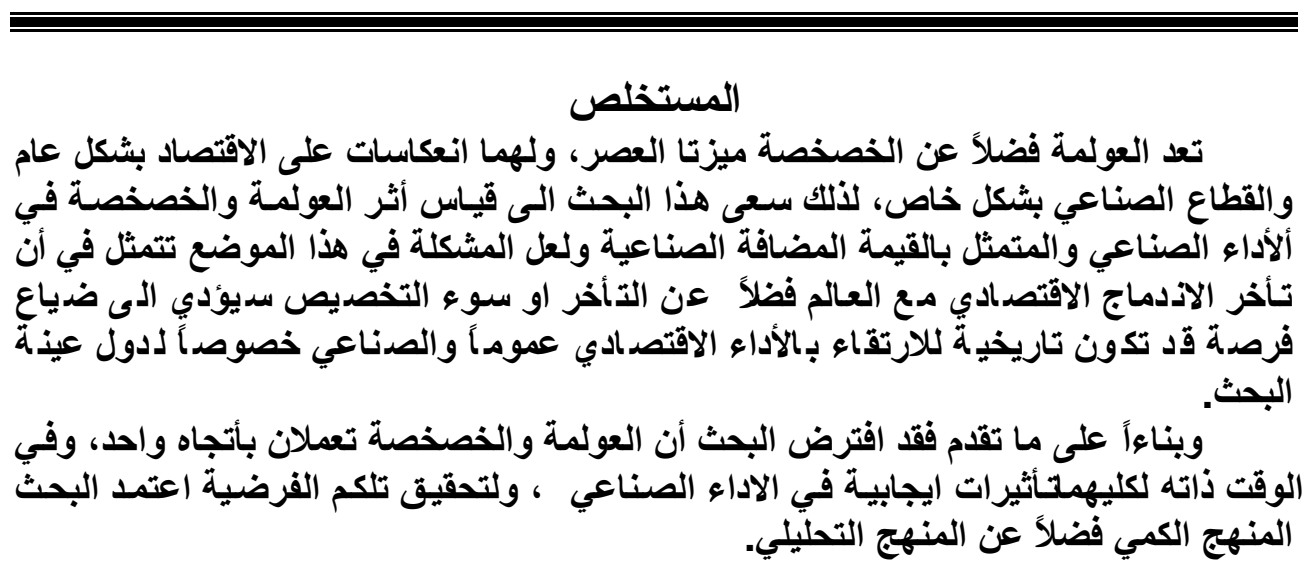

\title{
The Privatization, Globalization And Industrial Performance: Morocco As A Case Study
}

\author{
Dr. Anmar A. Haji \\ Assistant Professor \\ Dept. of Economics \\ University of Mosul
}

\author{
Rabah Jamil Al Khateeb \\ Assistant Lecturer \\ Dept. of Economics \\ University of Mosul
}

\begin{abstract}
Globalizations in addition to privatization are regarded to be the property of the age and both have their reflections on the economy in general and on the industrial sector in particular. Therefore, this research has endeavored to measure the effect of globalization and privatization on the industrial performance which is represented by the added industrial value and perhaps the problem of this topic is represented by the delay of economic merger with the world, in addition to the delay or the misuse of allotments which can lead to the loss of a chance which might be historical. That could uplift the economic performance in general and industry in particular in Morocco.

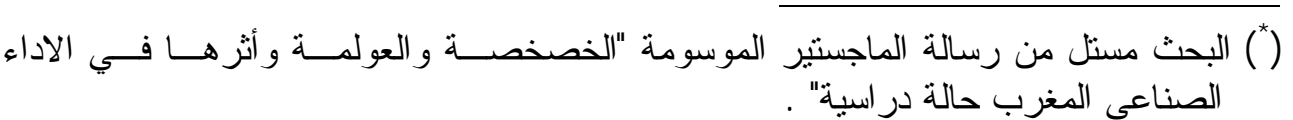

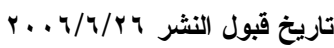

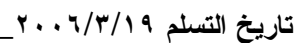


Based on the above, research supposed that globalization and privatization work are in the same direction during a particular period of time and both have positive effects on the industrial performance, they prove that supposition and research have adopted a quantities method in addition to comparative analytical method for a specimen of Morocco using time series covering the years $1980-2002$

\section{المقدمة}

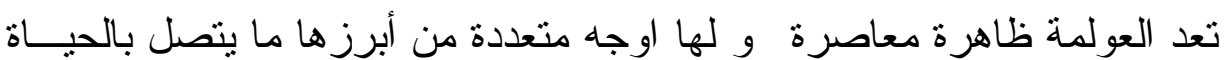

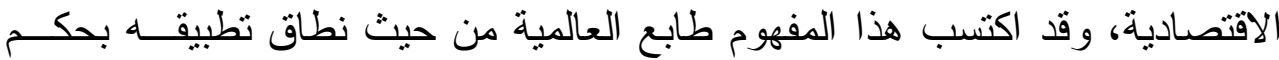

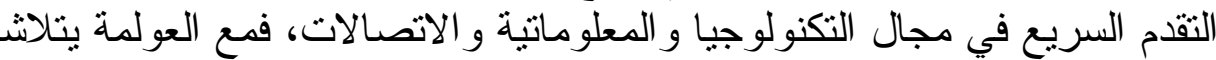

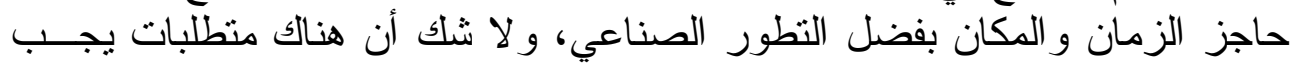

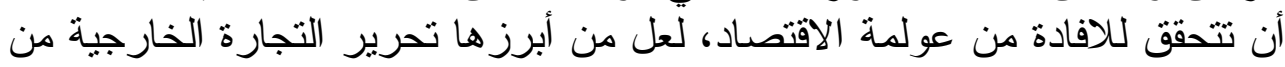

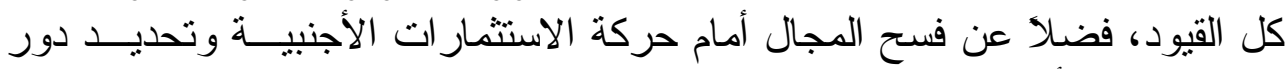

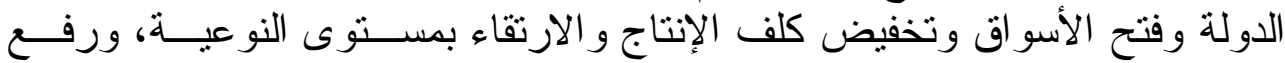

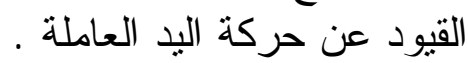

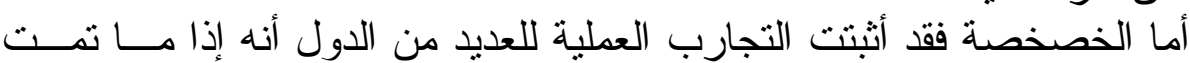

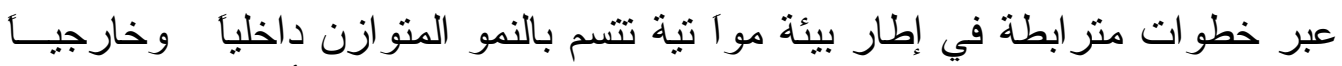

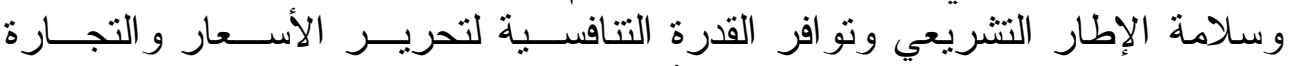

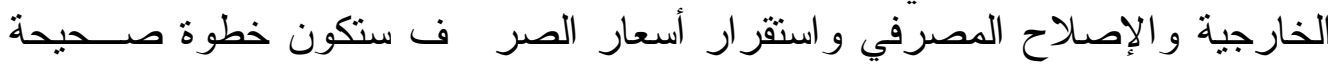

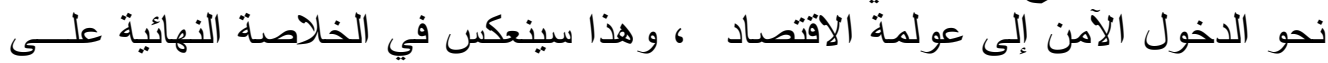
الأداء الاقتصادي عامةُ و الصناعي خاصةُ في المغرب. الاصن.

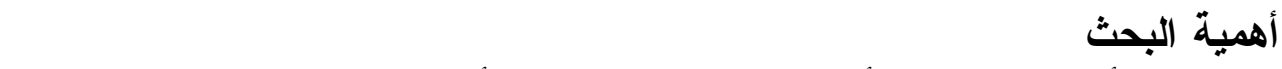

تبرز أهمية البحث فئن العولمة و الخصخصة أصبحتا مبز تي العصر ، ولهما

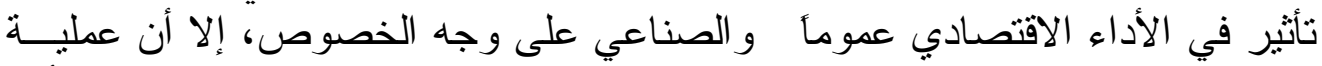

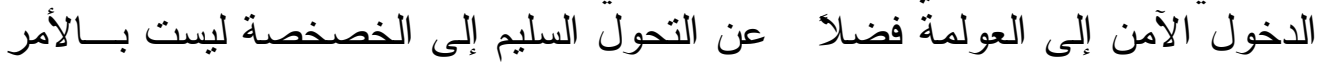

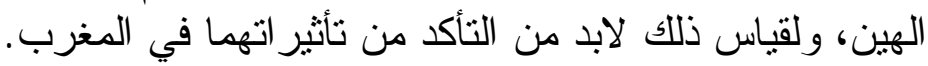

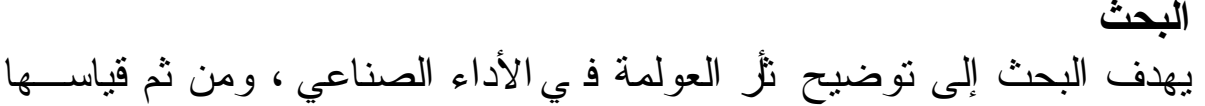

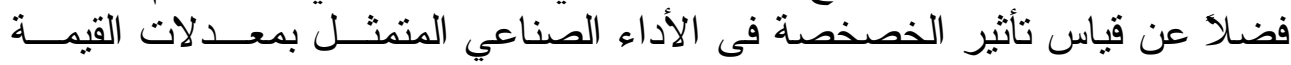

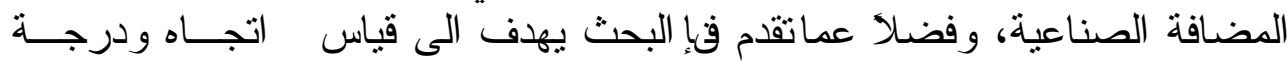
الارنباط بين العولمة و الخصخصة وفية في المغرب.

\section{مشكلة البحث}

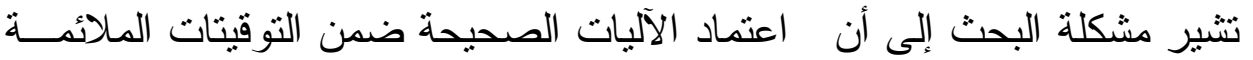

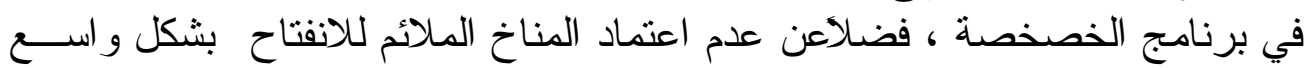




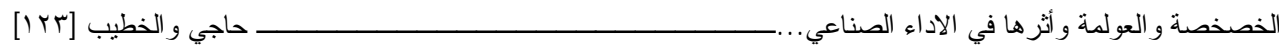

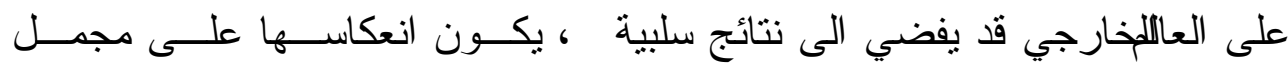

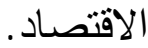

فرضية البحث

لقد افترض البحث فرضيتين أساسيتين:

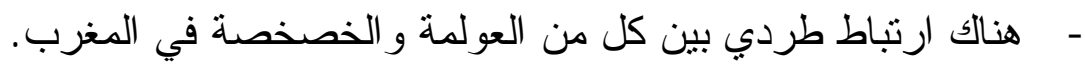

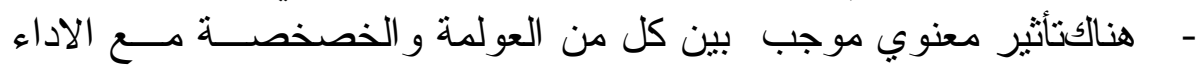

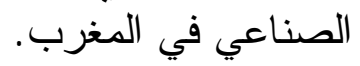

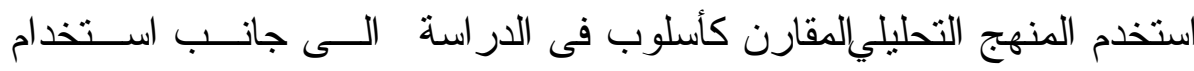
منهج البحث

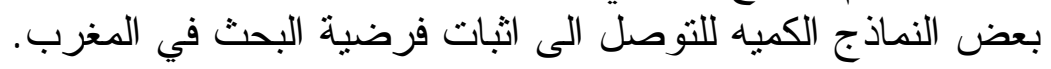

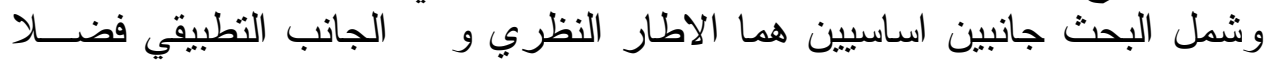
عن المقدمة و الاستتناجات و المقترحات.

\section{الاطار النظري

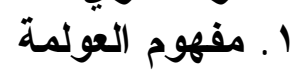

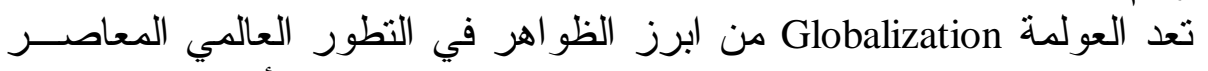

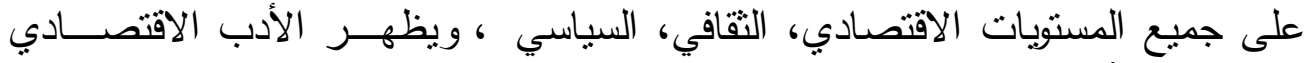

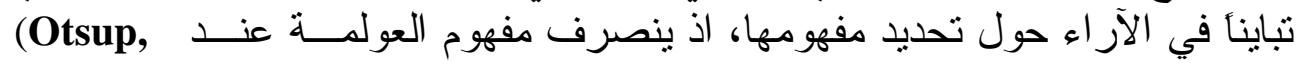
دول 1996, 1)

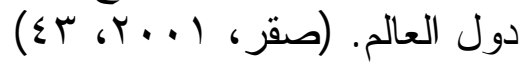

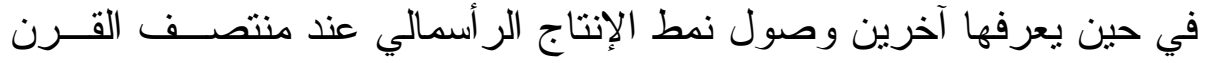

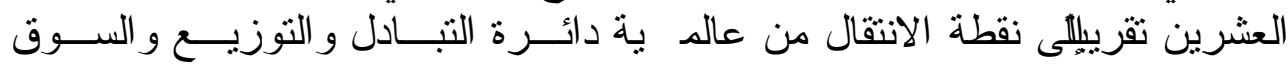

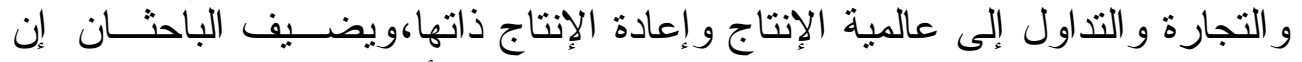

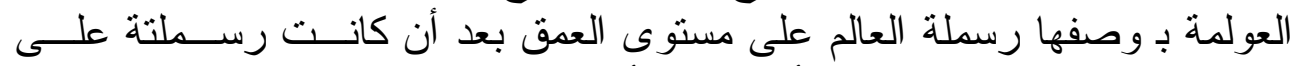

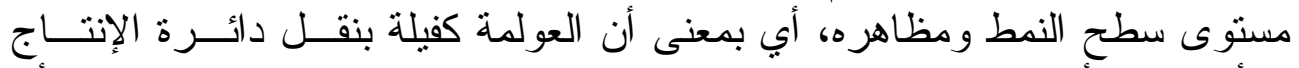

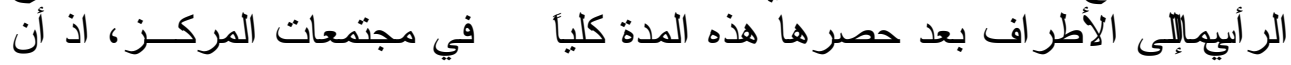

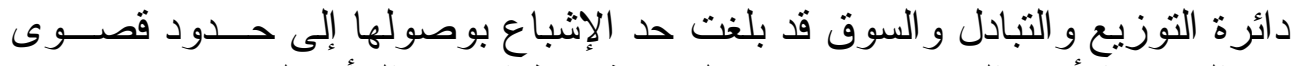

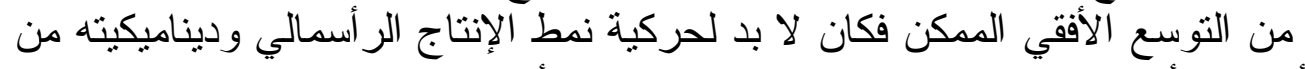

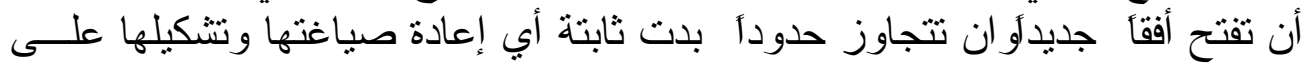

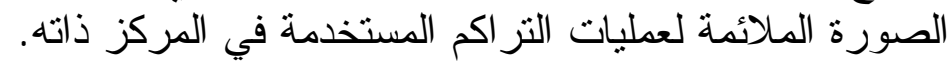

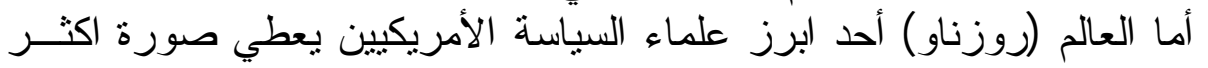

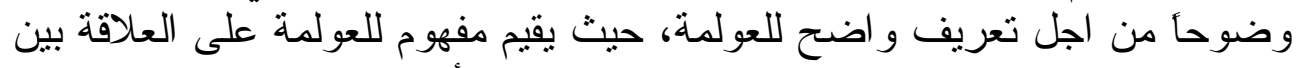

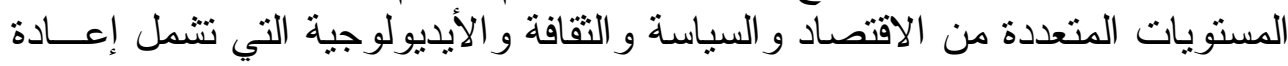




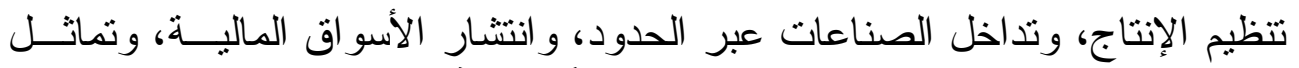

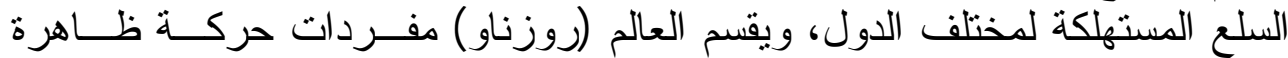

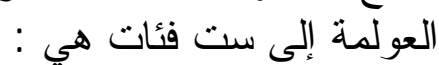
البضائع و الخدمات، الأفر اد، الأفكار و المعلومات، النقود، المؤسسات، أثـــكال

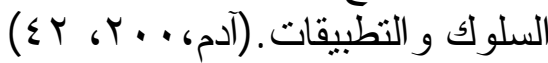

\section{r. بحددات العولمة الاقتصادية}

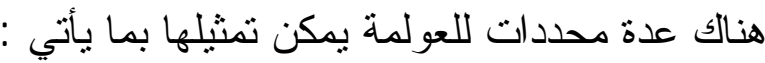
أ. الاستثمار الأجنبي المباشر:

ينطوي الاستثمار الأجنبي المباشر على تملك المستثمر الأجنبي لجـزءء مـــن

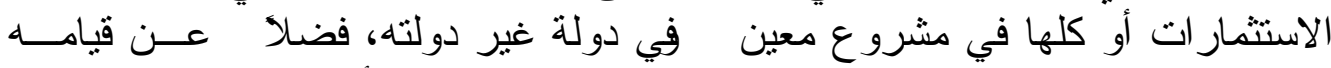

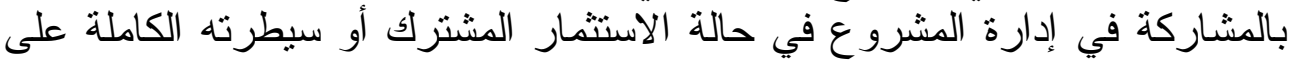

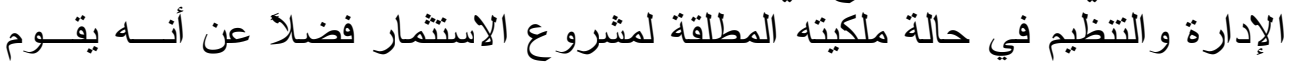

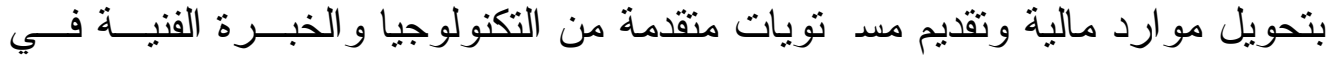

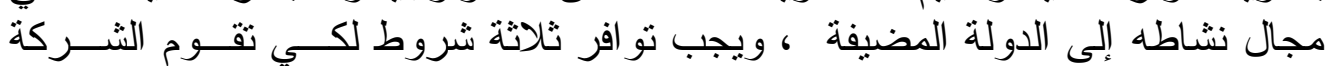

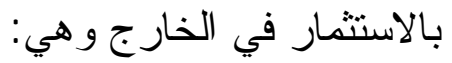

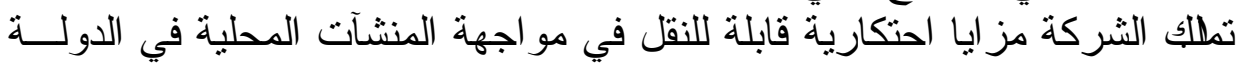
المضبفة.

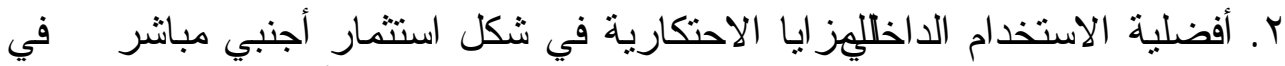
الخارج عند الاستخدامات البديلة لهذه المزايا منل التصدير أو التراخيص.

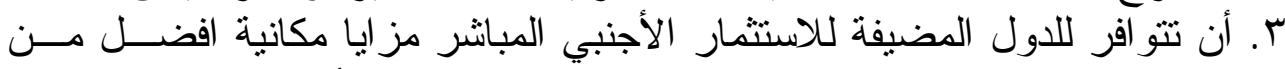

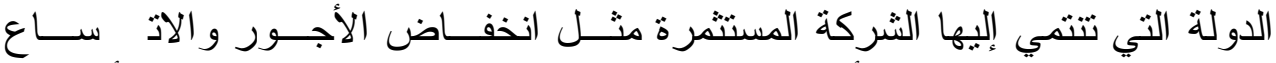

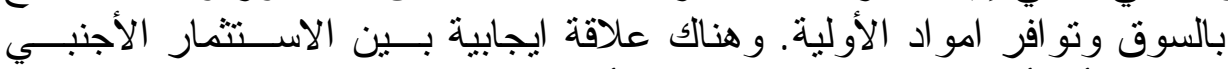

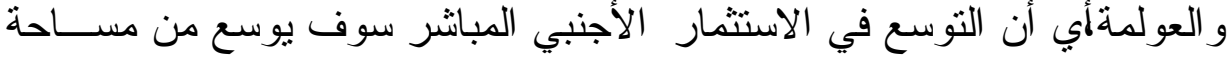
العولمة (Nands, 1981, 9-10)

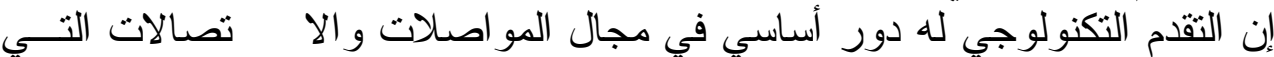

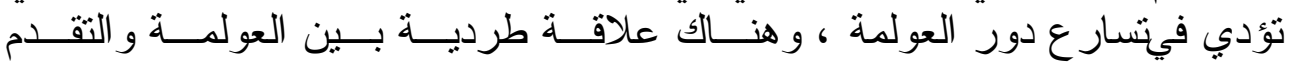
التكنولوجي (Lipsey, 1992, 188)

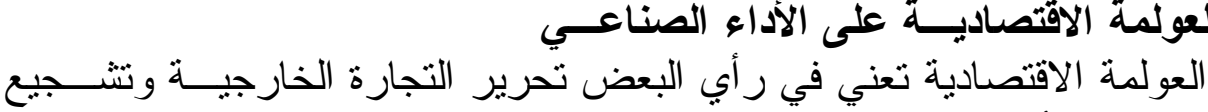

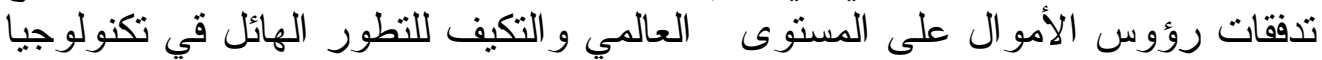
المعلومات و الانفتاح السياسي الايمقر اطي والي الاعتماد المنبادل بين الدول. 
وكذلك تؤدي العولمة الاقتصادية إلى تكامل الإنتاج و التوزيع و استخدام الســلـع

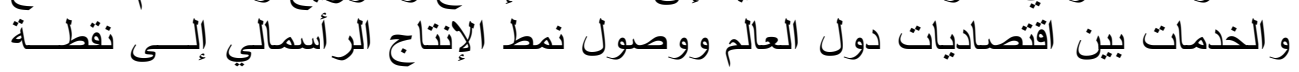

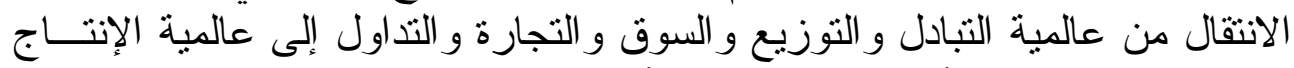

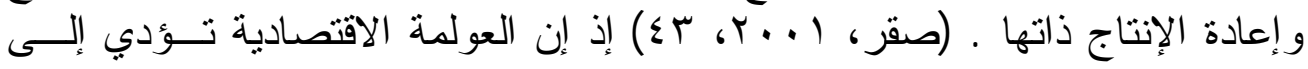

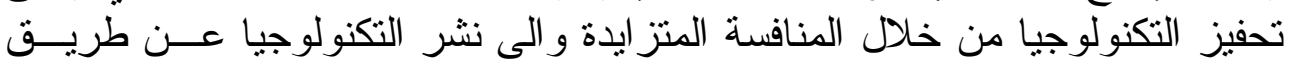

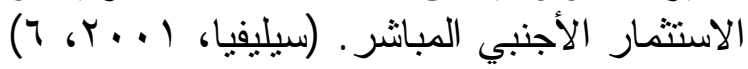

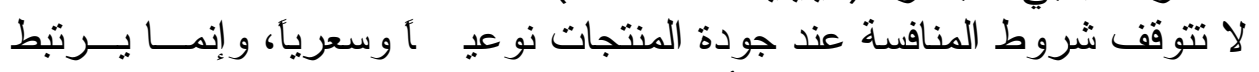

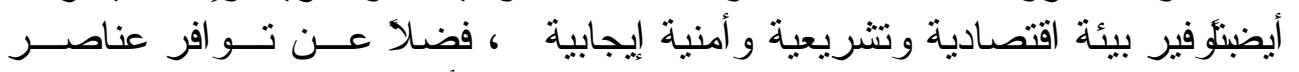

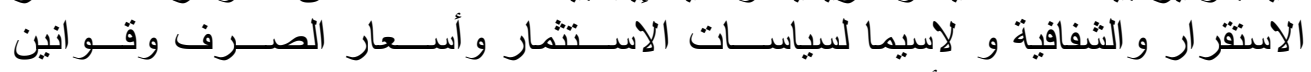

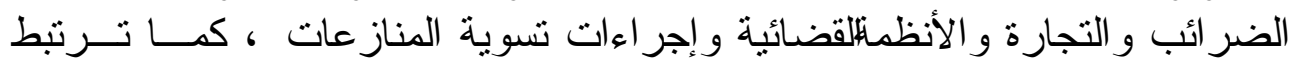

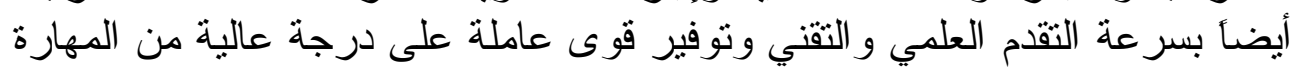

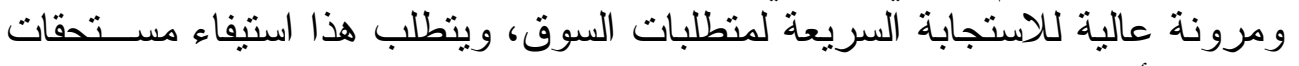

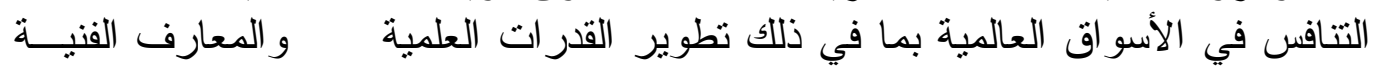

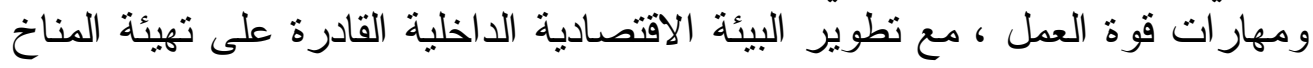

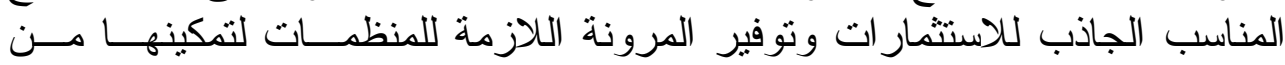

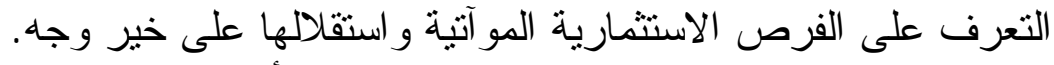

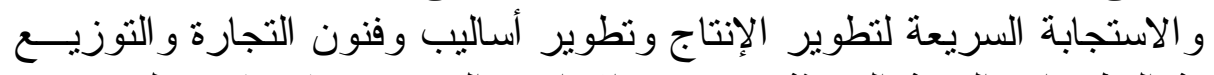

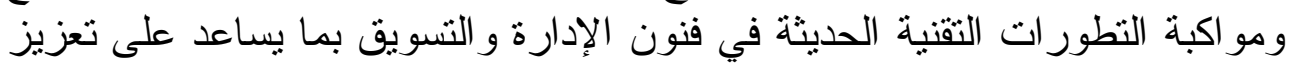

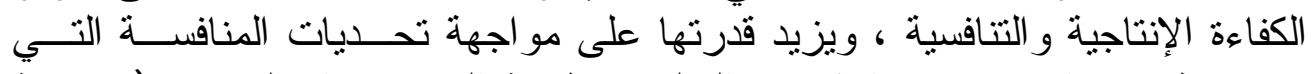

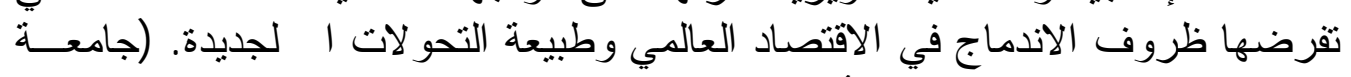

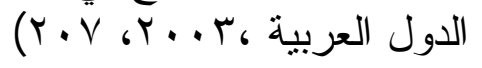

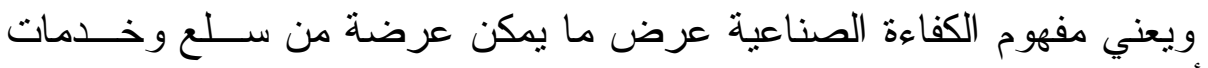

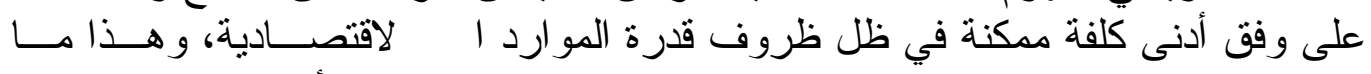

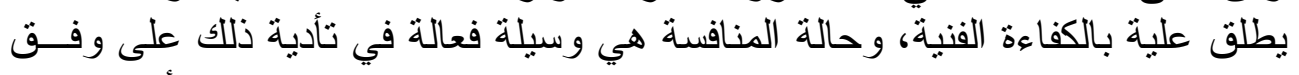

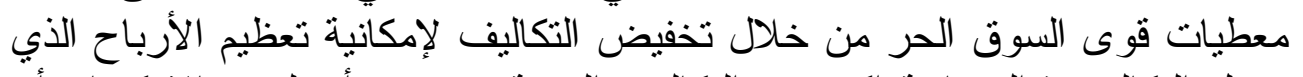

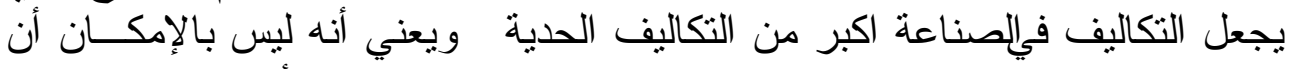

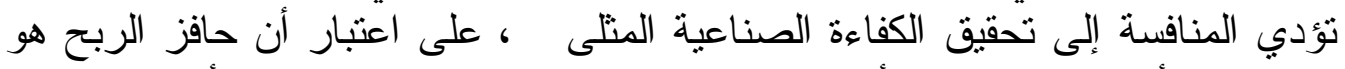

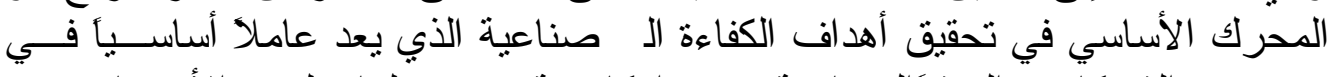

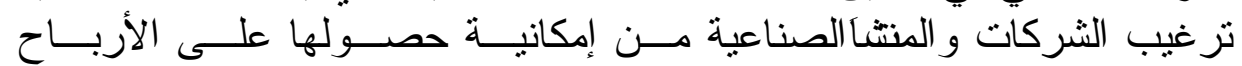

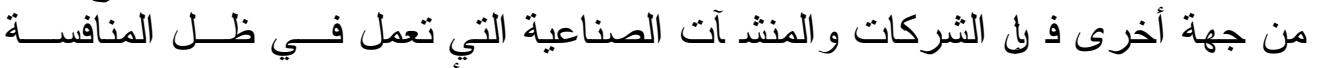

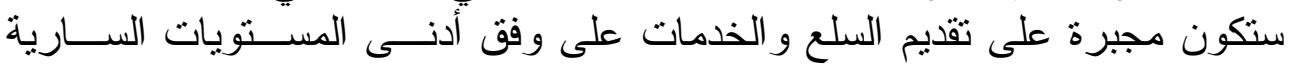

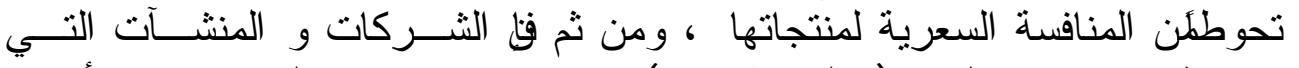

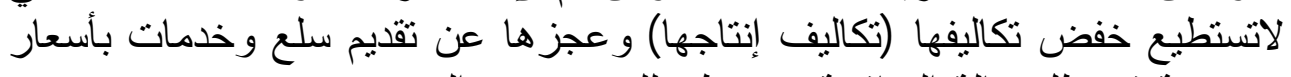

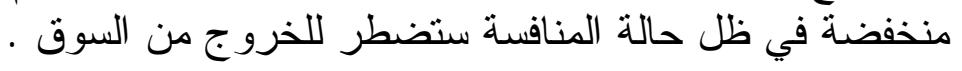




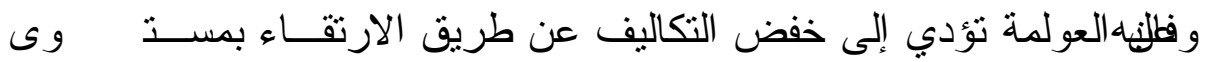

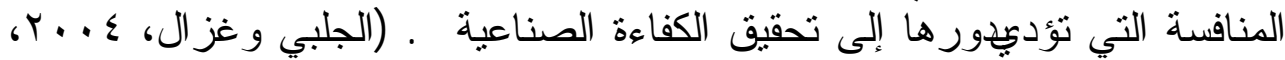
.) (1) - 1.0

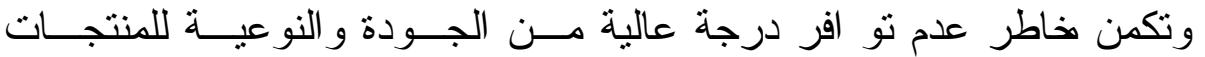

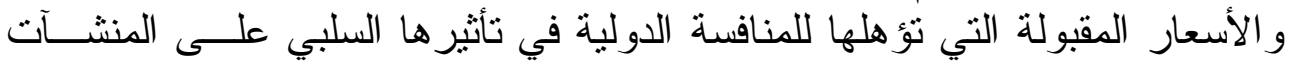

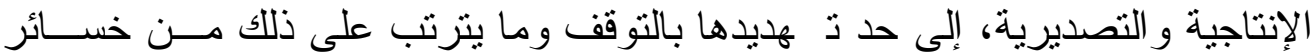

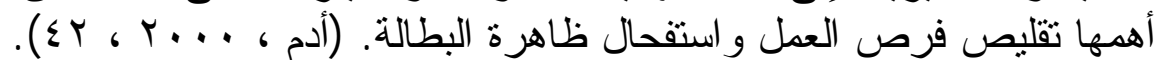

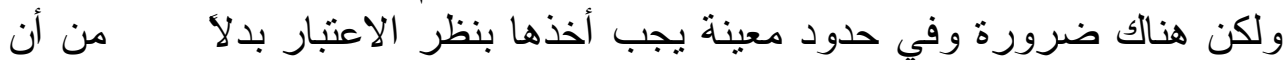
نفترض بأن حالة المنافسة تقود دائماً إلى تحقيق حالة الكفاءة الكفاءة الصناعية المتلى.

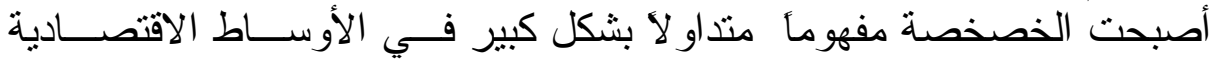

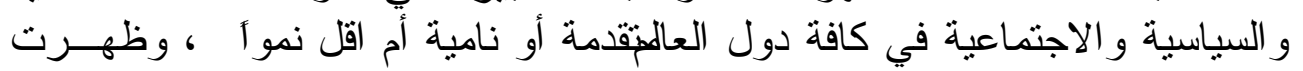
تعاريف و اجتهادات كثيرة لمعنى الخصخصة.

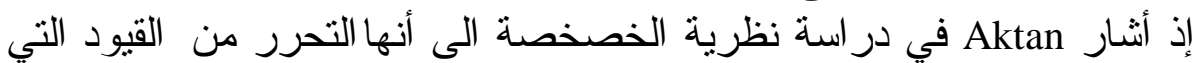

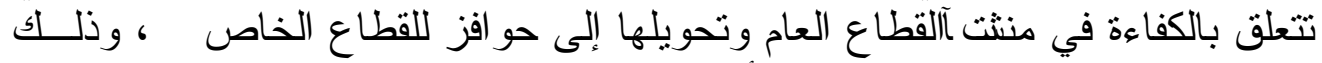
لزيادة قوى السوق Market Forces أو تقوية اقتصــاد الســوق Market Economic

(Aktan, 1995, 2) Fre ويمكن أن تعبر الخصخصة عما يأتي : (Aktan ا ـ نقل الملكية أو التحكم Control من القطّاع الخاص إلى القطاع العام.

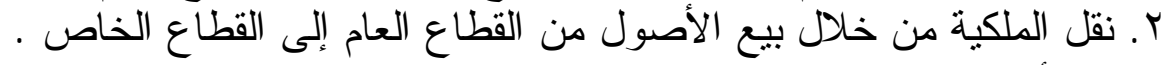

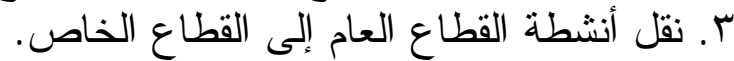

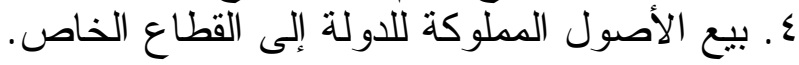

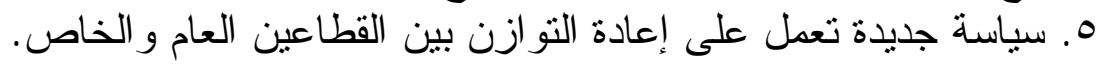
7 ـ تقسيم جديد للعمل بين القطاعين العام و الخاص.

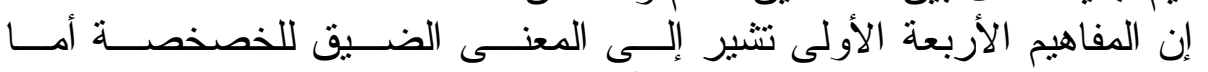
المفهومين الآخرين فيشير ان إلى المعنى الأوسع. (Jiyad, 1995, 10)

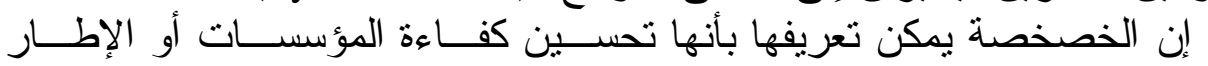

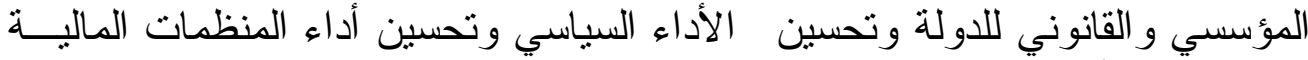

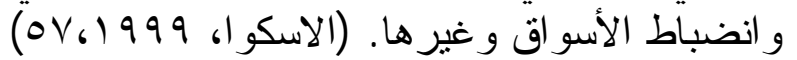

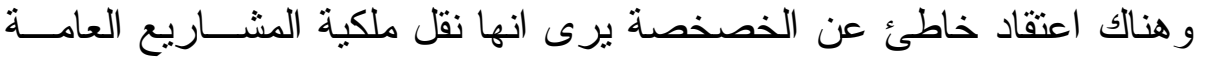

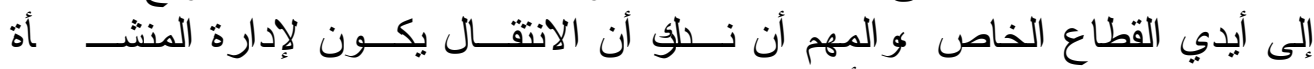
Corporat Governance

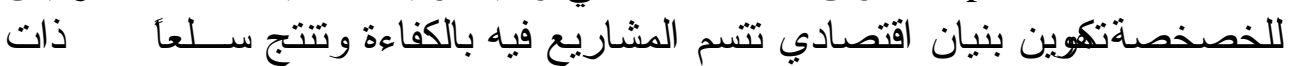


جودة مرتفعة وخدمات عند مستوى سعري حقيقي اقل المستقيدون من الخصخصة

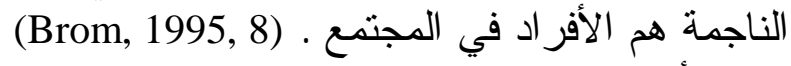

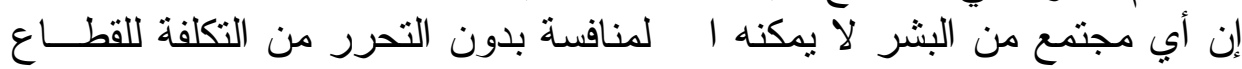

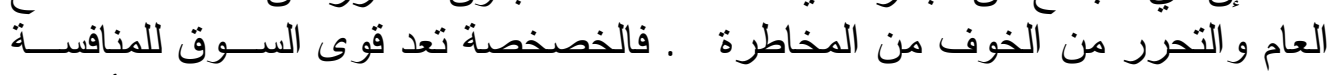

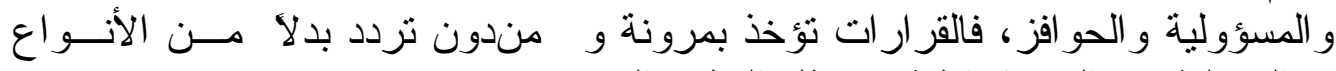
المختلفة من البيروقر اطية في ظل القطاع القاع العام. (Neew, 2003, 15)

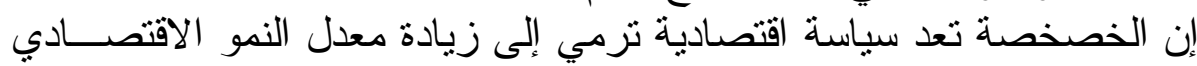

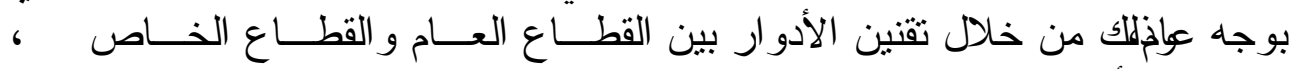

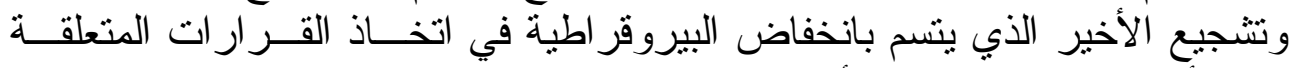

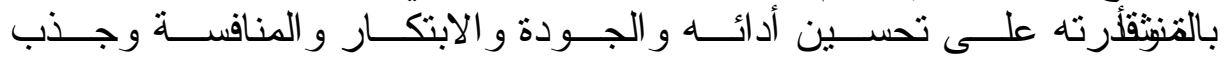

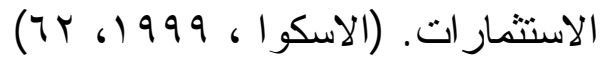

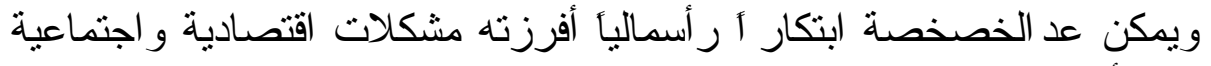

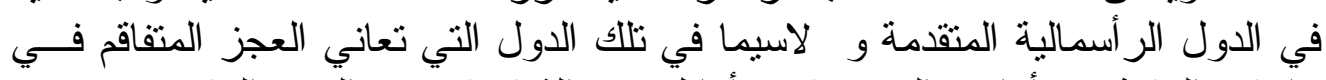

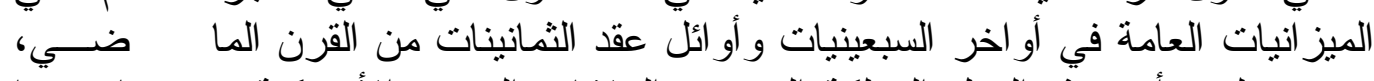

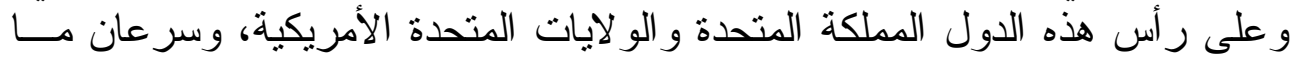

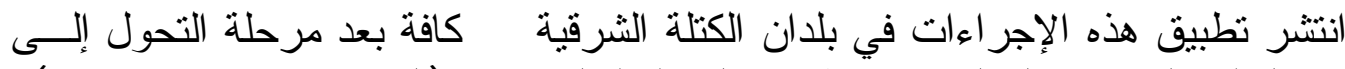

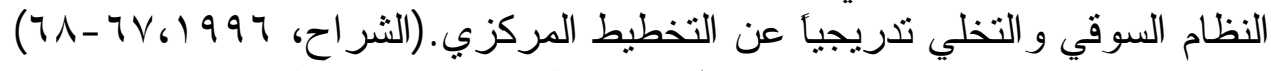

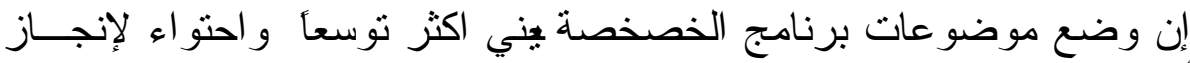
جزء أساسي في تقييم ورفع لفعالية الاقتصاد الجزئي. (Eellepe and Ski, 1995,35)

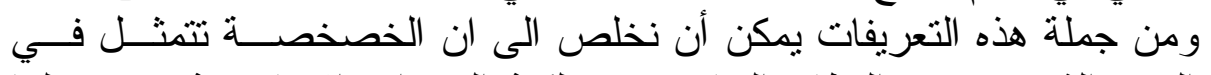

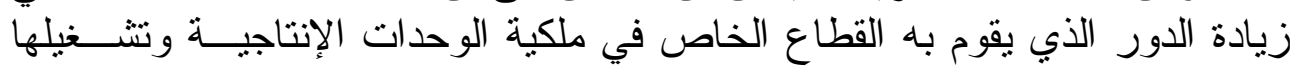

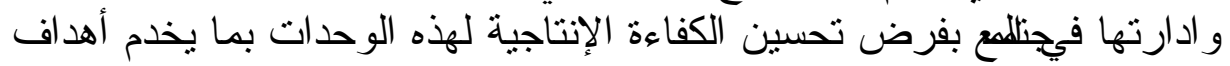

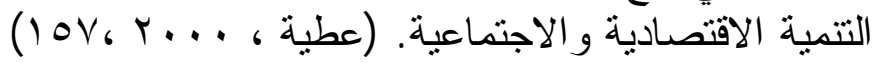

\section{العوامـلـل المحــددة لبرنامـج الخصخصة}

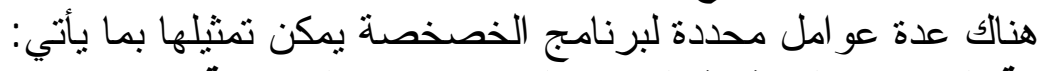

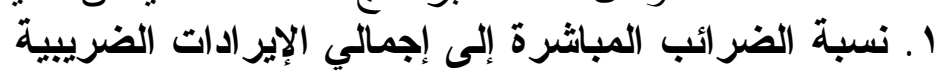

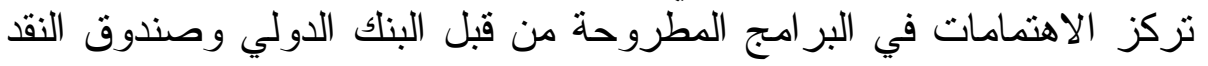

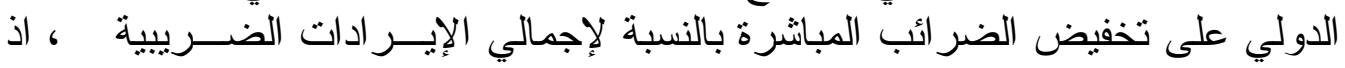

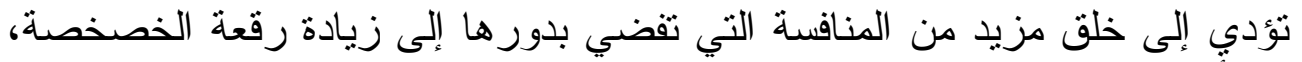

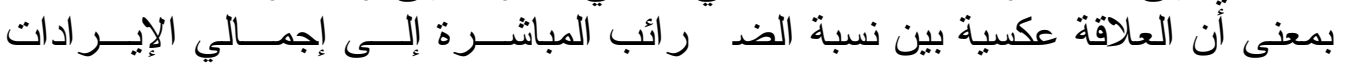

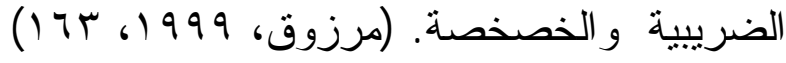




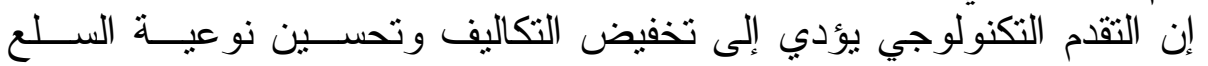

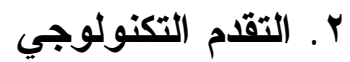

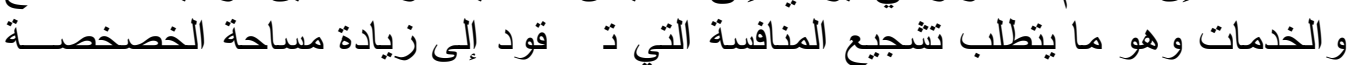

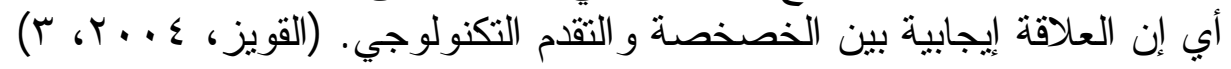

\section{أثــر برنـامج الخصخصة في كفاعة الأداء الصناعي}

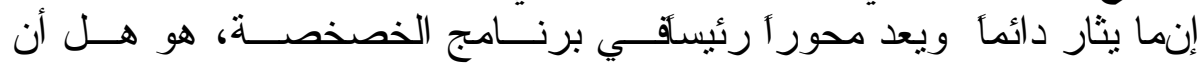

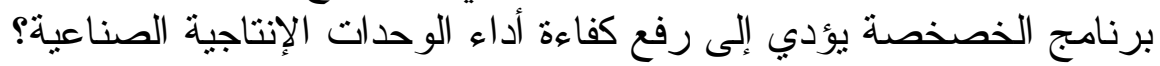

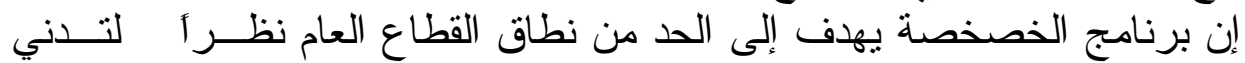

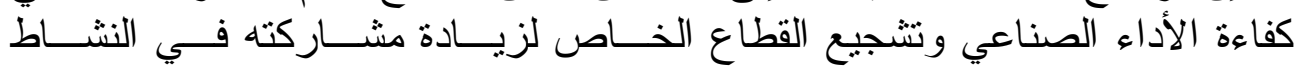

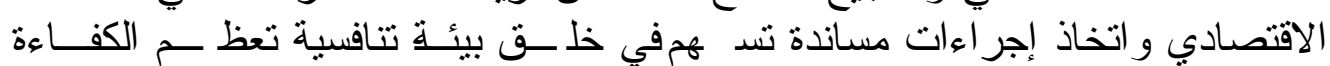

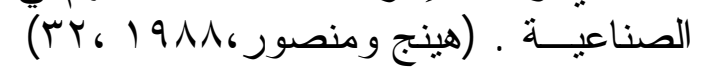

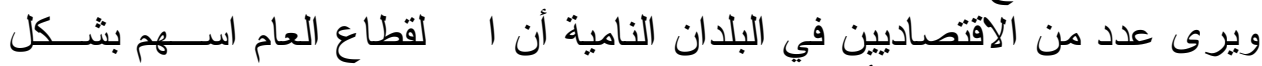

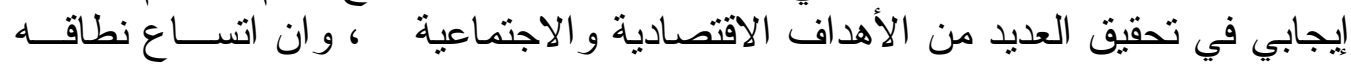

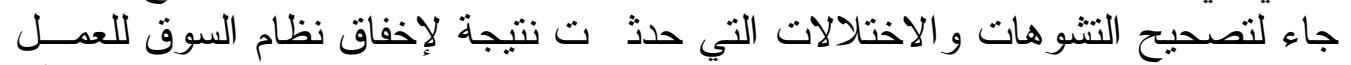

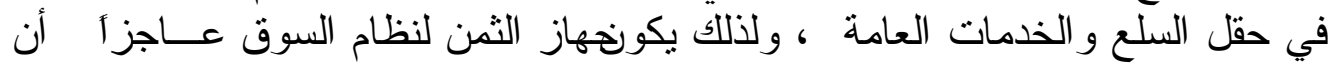
يعكس الكلفة و المنفعة الحدية الحقيقية الاجتماعية.

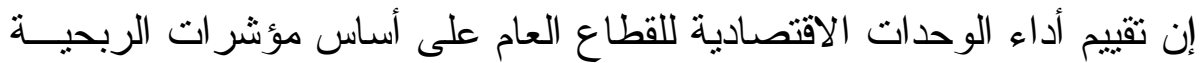

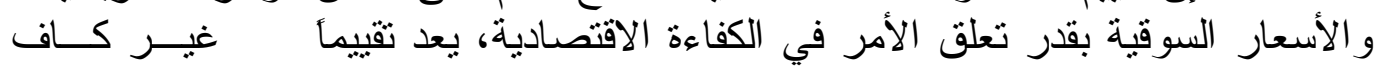

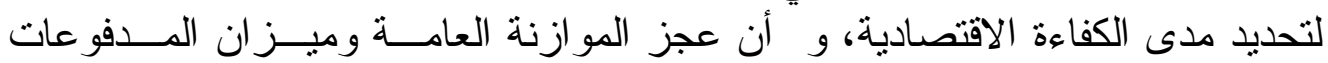

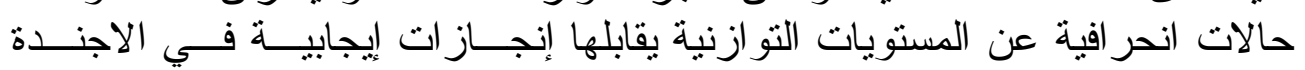

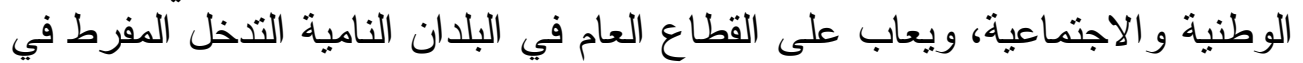

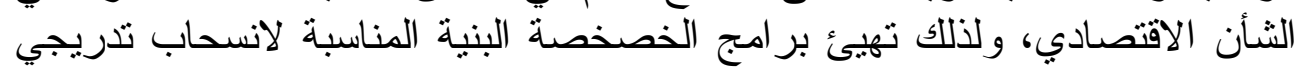

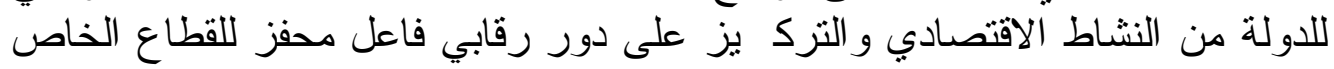

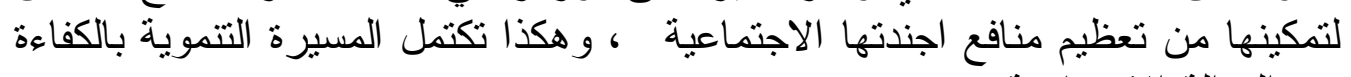

وبقدر تعلق الأمر بالبلدان العربية فان تفاقم أزماتها الاقتصادية واســتمر ارية

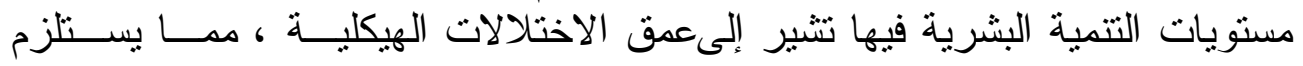

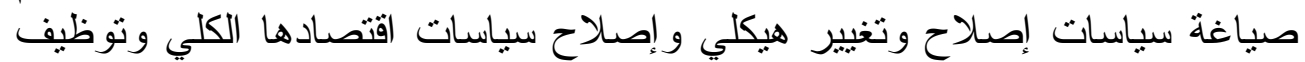
بر امج الخصخصة بما يخدم المصالح الّوطنية و الاستغلال الأمثل لمو اردهاً الوطنية.

\section{توصيف النماذّية القياسية}

تتشأ العلاقة بين المتغير ات علىوفق اسس ســبيية اذ إن هــــه المتغيــرات

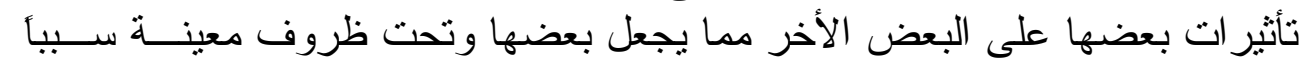


في حدوث ظاهرة أخرى تسمى نتيجة، وعليه ف

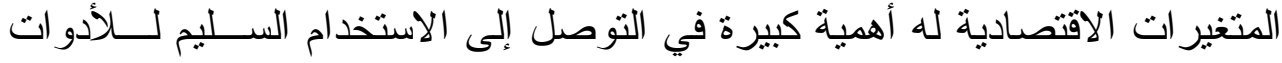
الإحصائية و الرياضية. الإنية.

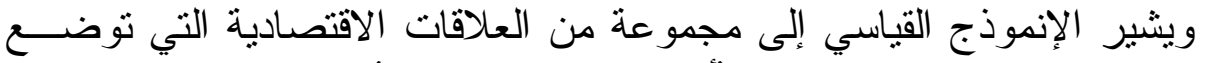

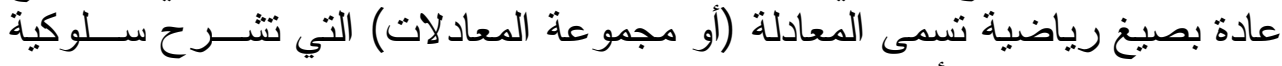
العلاقات لقطاع معين أو للاقتصاد ككل.

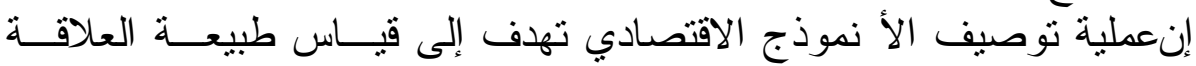

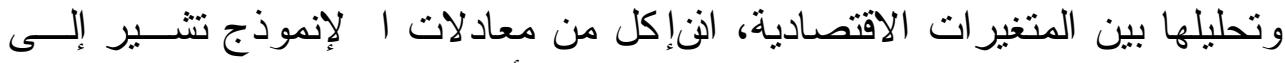

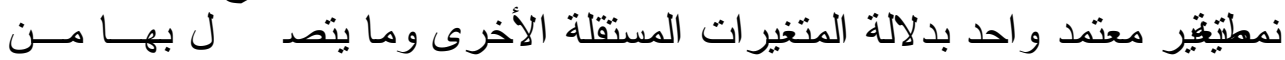

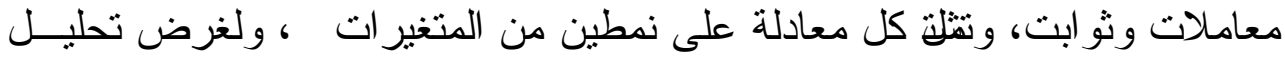
هذا الأثر تم اعتماد طريقة المربعات الصغرى ولى الاعتيادية على مرحلتين (2SLS) .

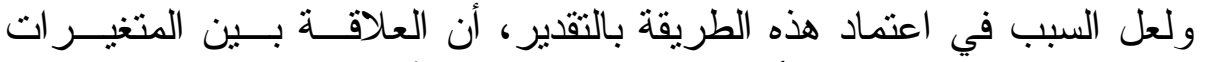

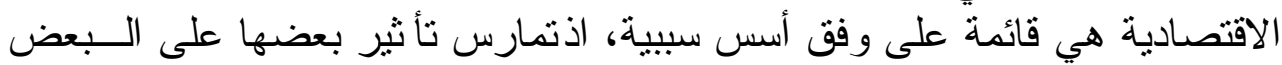

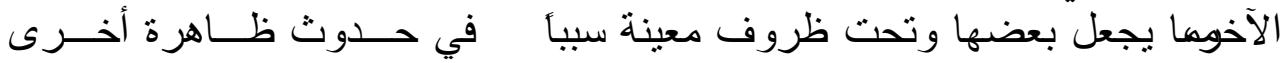

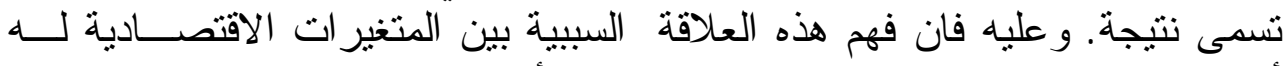

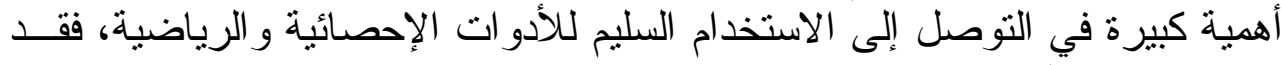

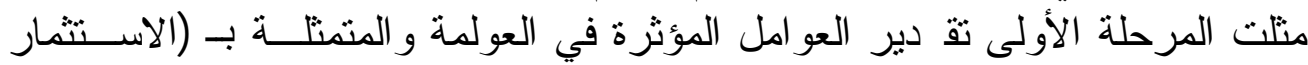

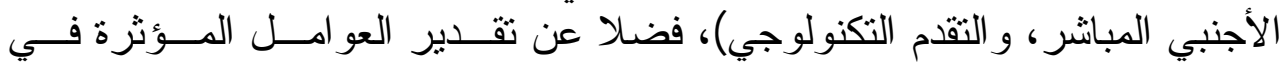

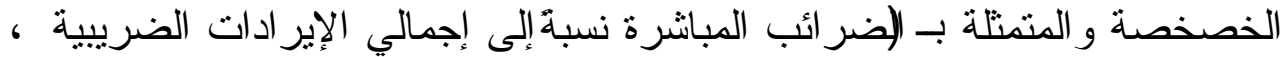
و التقدم التكنولوجي) .

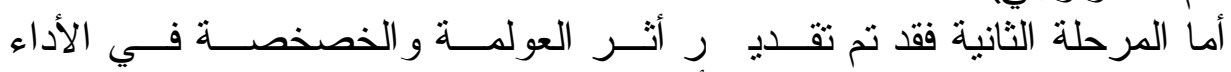

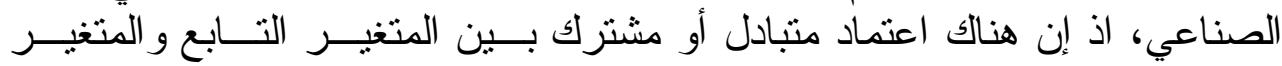

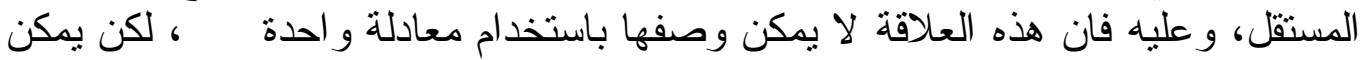

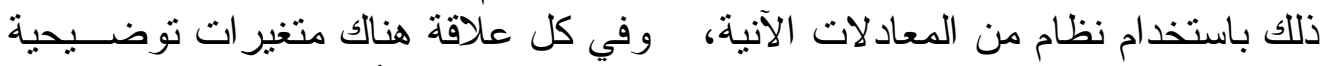

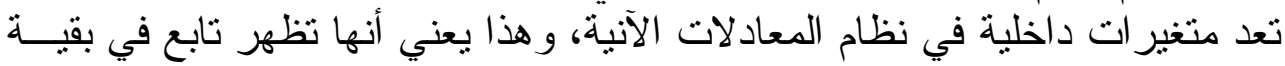

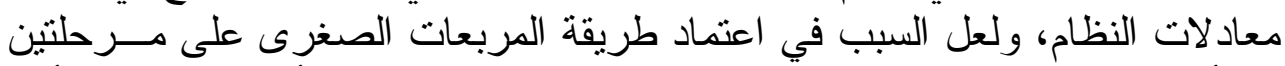

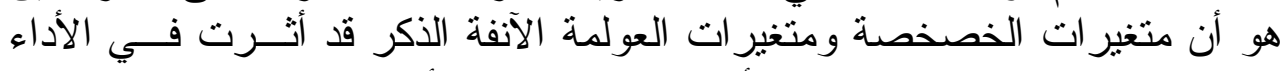

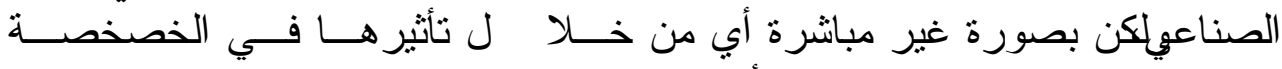

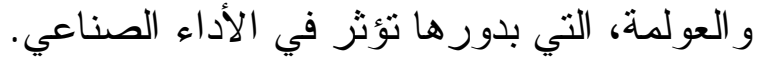

$$
\begin{aligned}
& \text { المرحلــة الأولى لـى } \\
& \text { تشمل تحديد المتغير ات المؤثزة في العولمة اذ إن : } \\
& \mathrm{Y}=\mathrm{B} 0+\mathrm{B} 1 \mathrm{X} 1+\mathrm{B} 2 \mathrm{X} 2+\mathrm{Ui}
\end{aligned}
$$




$$
\begin{aligned}
& \text { اذ إن } \\
& \text { العولمة : العية } \\
& \text { =X1 الاستثمار الأجنبي المباشر =X1 } \\
& \text { X2 } \\
& \text { Intercept الحد الثابت =B0 } \\
& \text { Coefficients معاملات المتغير ات =Bi }
\end{aligned}
$$

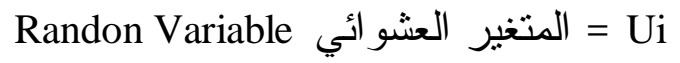

$$
\begin{aligned}
& \text { أما المتغير ات المؤثزة في الخصخصة فهي كما يوضحها الإنموذج آلاتي : } \\
& \mathrm{Y}=\mathrm{B} 0+\mathrm{B} 1 \mathrm{X} 1+\mathrm{B} 2 \mathrm{X} 2+\mathrm{Ui} \\
& \text { اذ إن } \\
& \text { Y = ان : الخصخصة =Y } \\
& \text { نسبة الضر ائب المباشرة إلى إجمالي الإير ادات الضريبية. X1 } \\
& \text { X2 } \\
& \text { Intercept الحد الثابت = B0 }
\end{aligned}
$$

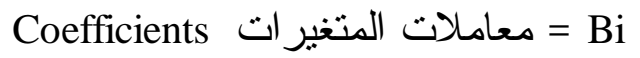

$$
\begin{aligned}
& \text { Randon Variable المتغير العشوائيرت =Ui }
\end{aligned}
$$

المرحــــة الثانيـــة

تشمل توصيف العلاقة بين العولمة و الخصخصة بوصفها متغيــر ات مســتقلة

$$
\mathrm{Y}=\mathrm{B} 0+\mathrm{B} 1 \mathrm{X} 1+\mathrm{B} 2 \mathrm{X} 2+\mathrm{Ui}
$$

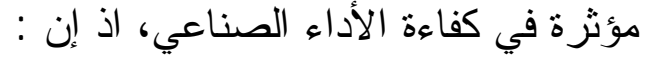

$$
\begin{aligned}
& \text { حيث أن : } \\
& \text { كفاءة الأداء الصناعي =Y } \\
& \text { X1 } \\
& \text { X2 =X2 الخصخصة } \\
& \text { B0 }
\end{aligned}
$$

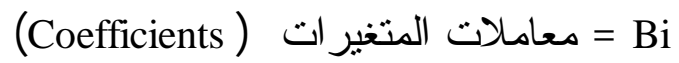

$$
\begin{aligned}
& \text { Ui } \\
& \text { وقد تم استخدام مستوى معنوية } 0.05 \text { و عدد مشاهدات }
\end{aligned}
$$

تقدير النماذج القياسية الخاصة بالمغرب وتحليلها

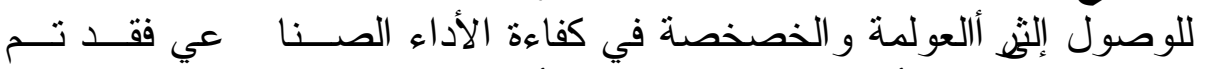

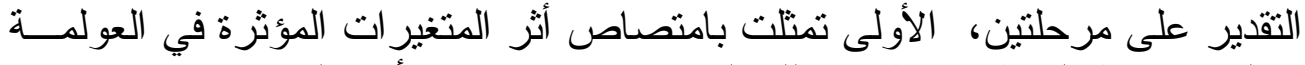

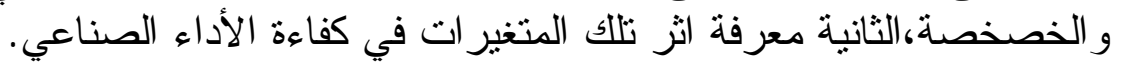




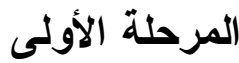

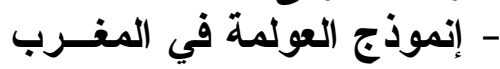

تقدير أثزر المتغير ات المحددة للعولمة و المتمنثلة بـ (نسبة الصـادر ات الصــــناعية

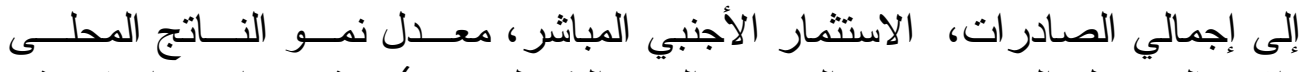

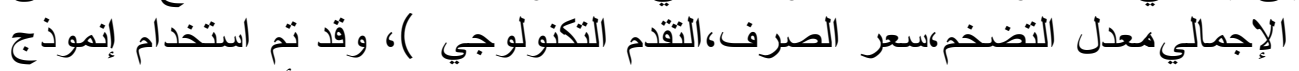

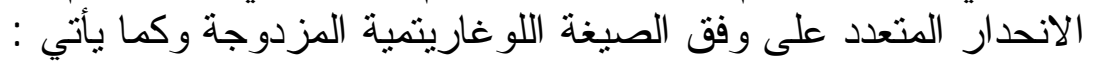
$\mathrm{Y}=-7.63+1.35 \mathrm{X} 1+3.15 \mathrm{X} 2$.

$$
\begin{array}{ll}
\mathrm{t} \quad 3.54 & 4.62 \\
\mathrm{R}^{2}=0.78 & \mathrm{R}^{-2}=0.75 \\
\mathrm{D} . \mathrm{W}=1.41 & \mathrm{~F}=34.38
\end{array}
$$

\footnotetext{
اذ إن$$
\text { =Y }
$$$$
\text { =X1 الاستثمار الأجنبي المباثر =Y }
$$$$
\text { X2 }
$$

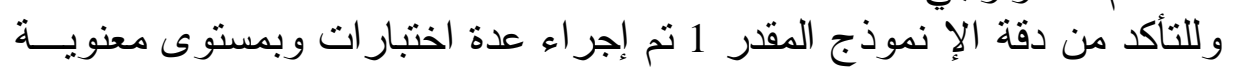

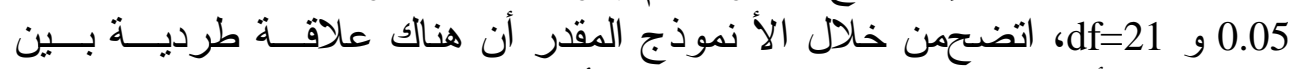

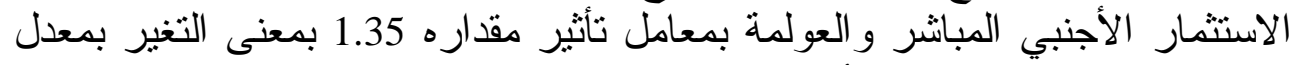

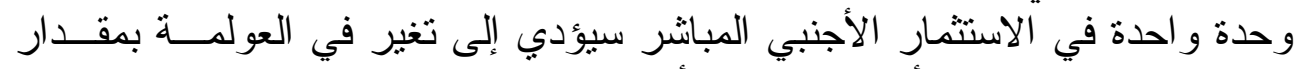

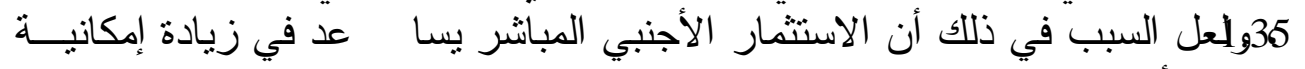

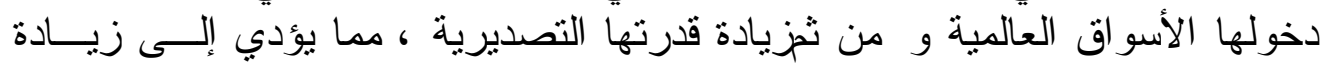
انفتاحها الاقتصادي.

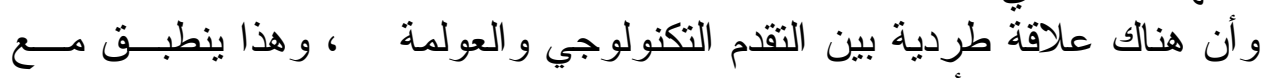

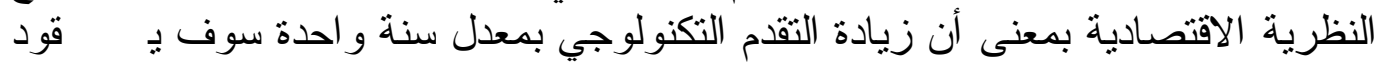

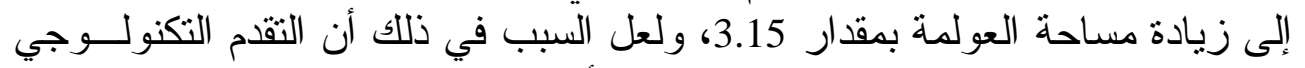

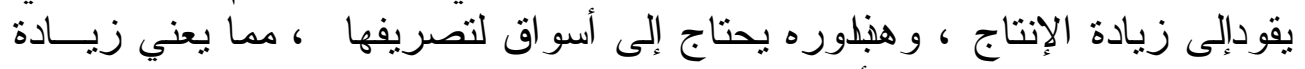

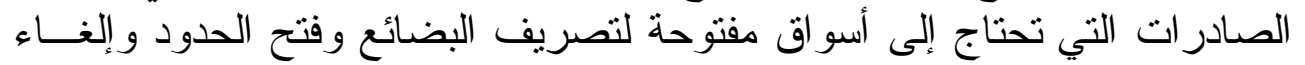

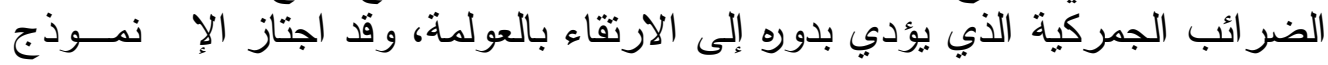

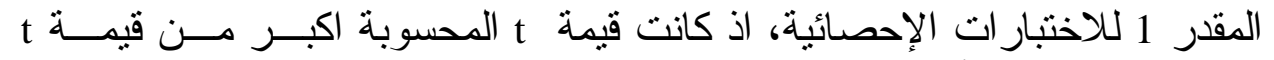

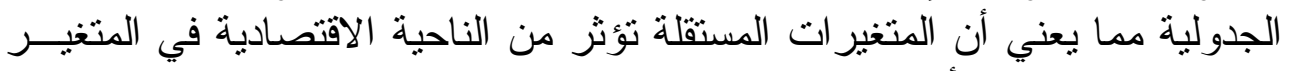

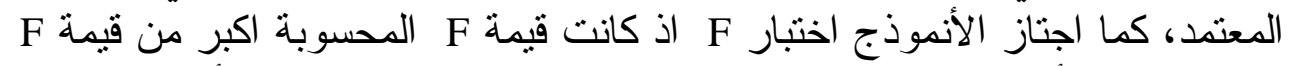

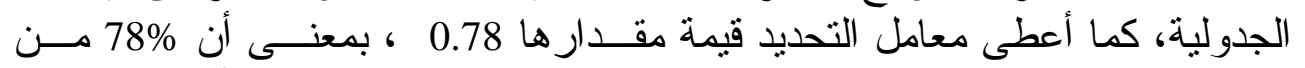

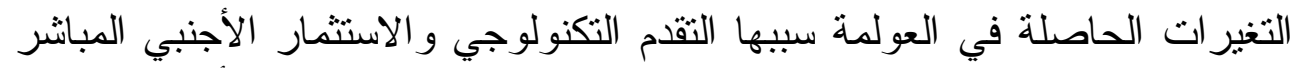

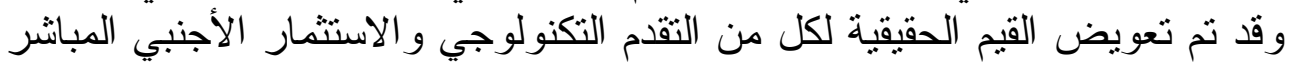
في الإنموذج المقدر وبذلك تم الحصول على القيم المقدرة للعولمة في المغرب.
} 


\section{-}

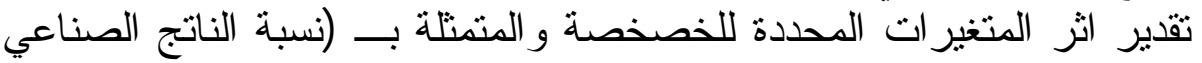

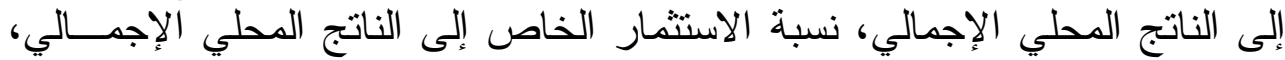

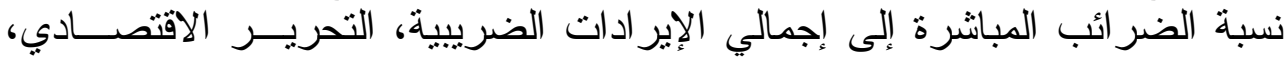

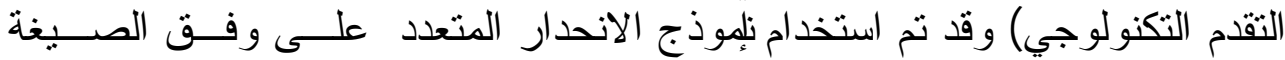

$$
\begin{aligned}
& \mathrm{Y}=1.08-0.04 \mathrm{X} 1+0.07 \mathrm{X} 2 \\
& \mathrm{t} \quad-2.78 \quad 8.03 \\
& \mathrm{R}^{2}=0.77 \quad \mathrm{R}^{-2}=0.75 \\
& \text { D.W }=0.75 \quad F=33.60
\end{aligned}
$$

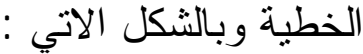

$$
\begin{aligned}
& \text { اذ إن : إن }
\end{aligned}
$$

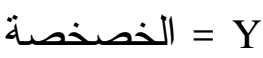

$$
\begin{aligned}
& \text { نسبة الضر ائب المباثرة إلى إجمالي الإير ادات الضريبية X1 }
\end{aligned}
$$

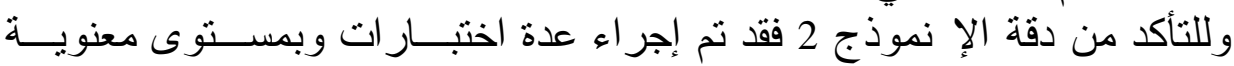

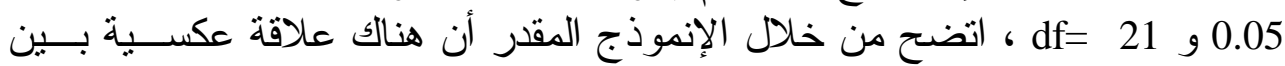

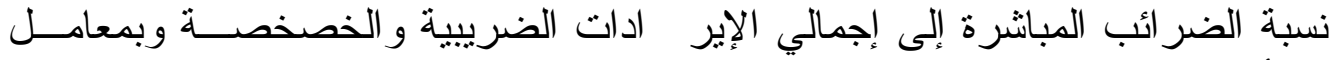

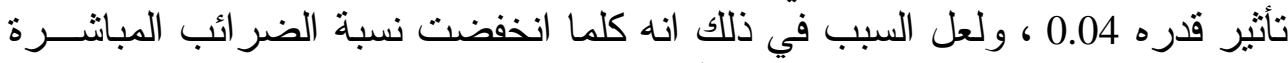

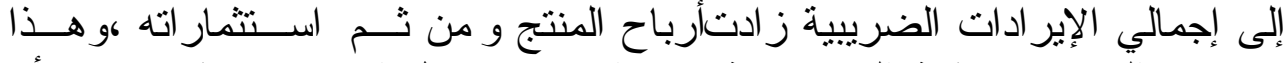

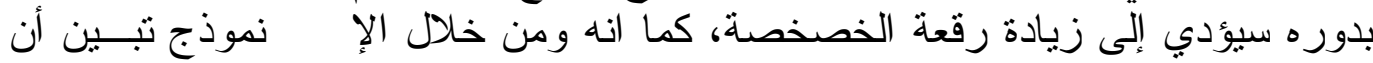

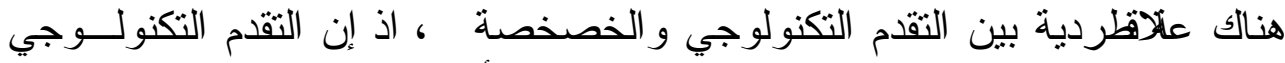

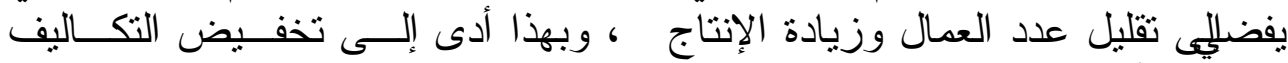

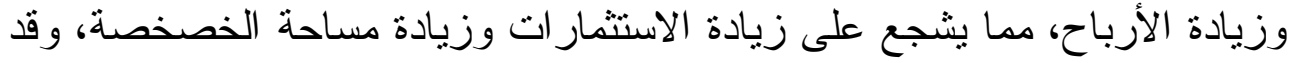

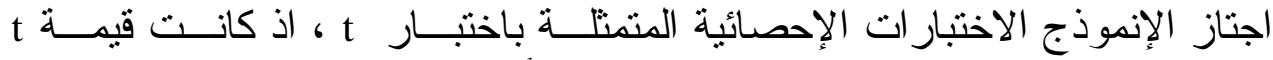

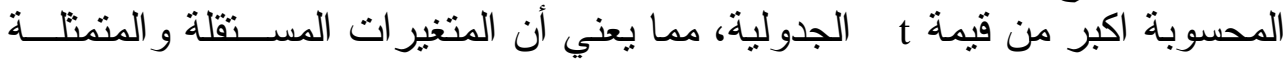

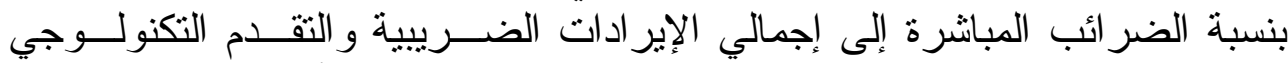

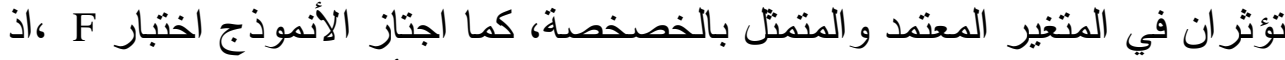

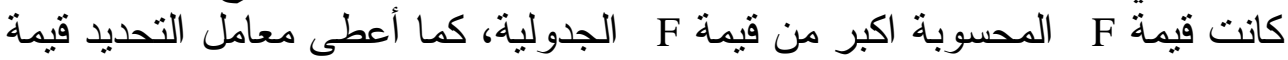

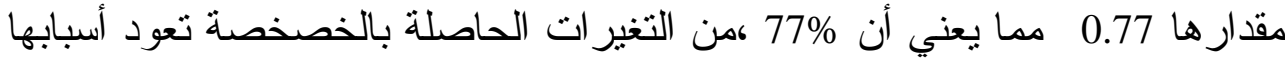

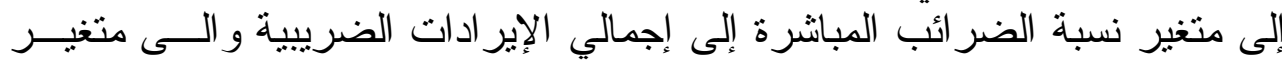

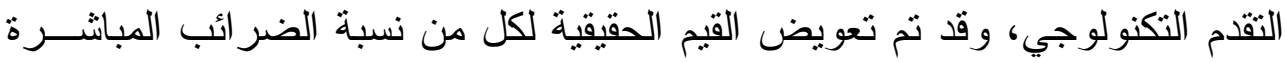

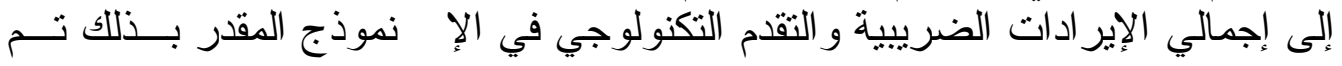

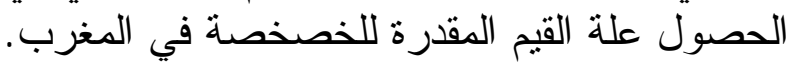


المــرحلة الثانبــة

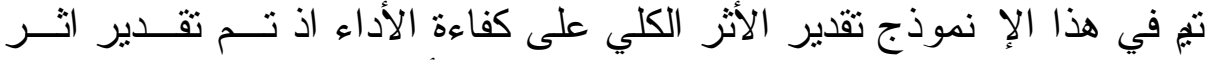

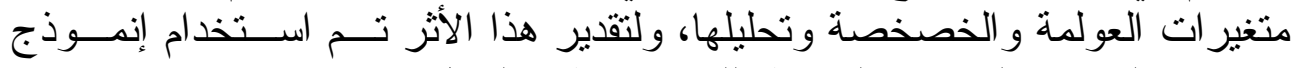
الانحدار المتعدد على وفق الصيغة اللوغ غاريتمية وبالثكل الاتي:

$$
\begin{array}{ll}
\mathrm{Y}=8.91+0.299 \mathrm{X} 1+0.225 \mathrm{X} 2 \\
\mathrm{t} \quad 2.36 & 1.94 \\
\mathrm{R}^{2}=0.95 & \mathrm{R}^{-2}=0.94 \\
\mathrm{D} . \mathrm{W}=1.62 & \mathrm{~F}=147.50
\end{array}
$$

$$
\begin{array}{r}
\text { =Y } \\
=\text { Sفاءة الأداء الصناعي }=\text { X1 } \\
\text { الخصخة }=\text { X2 }
\end{array}
$$

وللتأكد من دقة الإنموذج 5 ت تم إجراء عدة اختبار ات وبمستوى معنوية 0.05

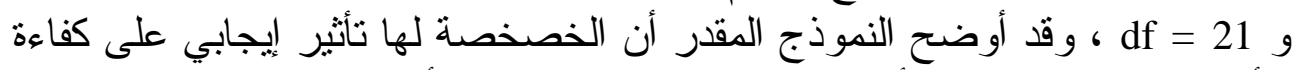

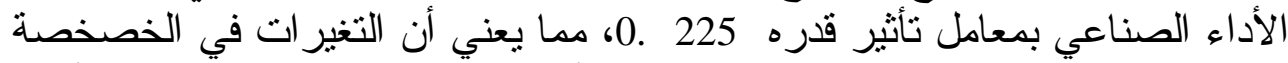

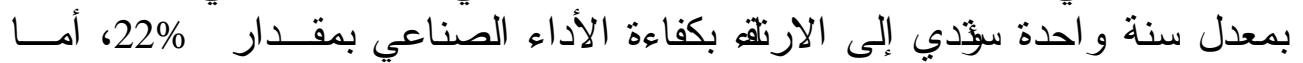

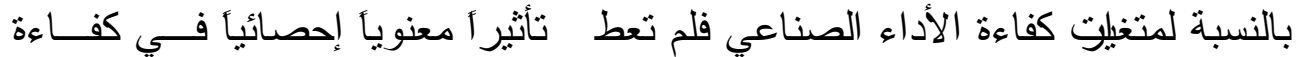

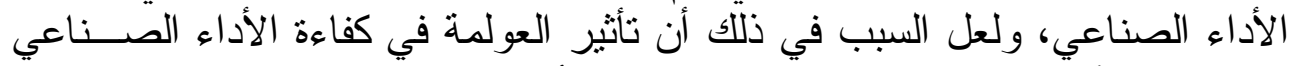

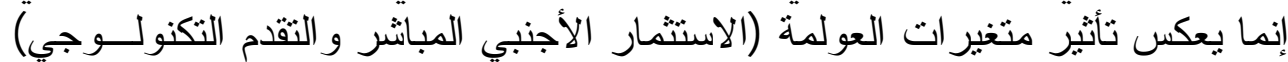

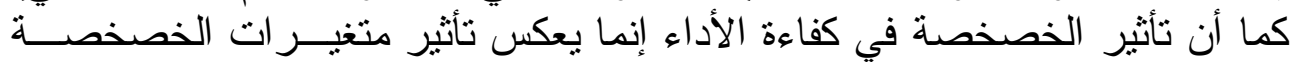

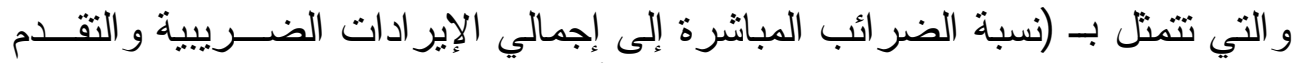

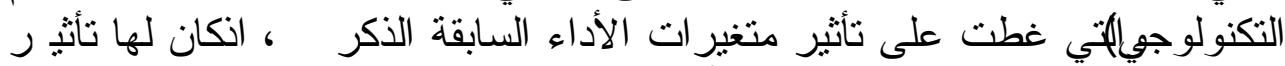

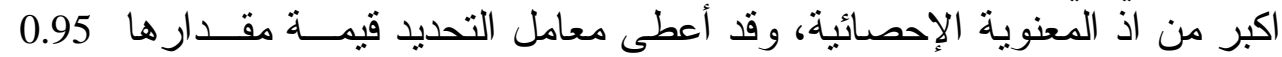

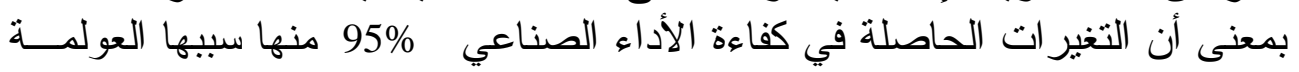

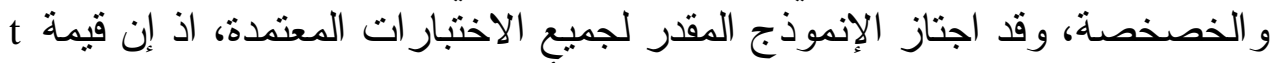

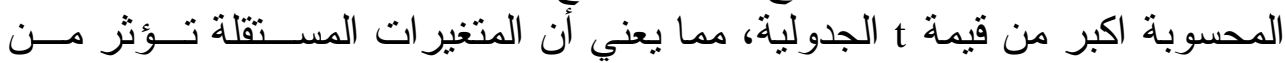

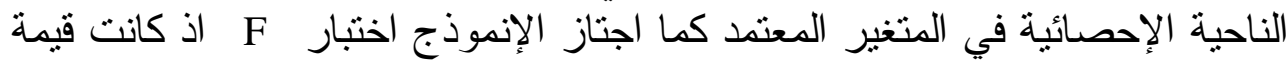
F المحسوبة اكبر من قيمة F F Fلية الجدولية.

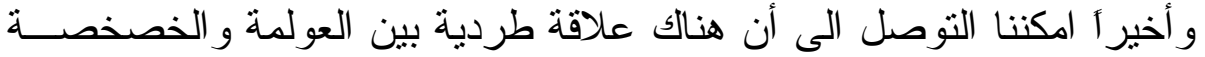

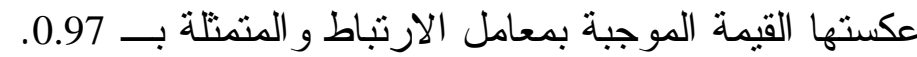

\section{الاستنتاجات و التوصيات اولاً - الاستنتاجات والتوات}

ا . ضرورة وضع ضو ابط من قبل الحكومة فيما يتعلق بالاستثمار الاجنبي المباشر

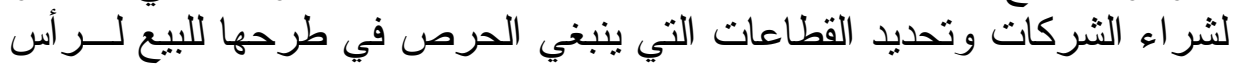
مال خاص اجنبي منعأ للهيمنة او الاحتكار . 
r. في ظل سياسة الخصخصة وتخلي الحكومة عن بعض ملكيتها للقطاع الخــاص الخداص

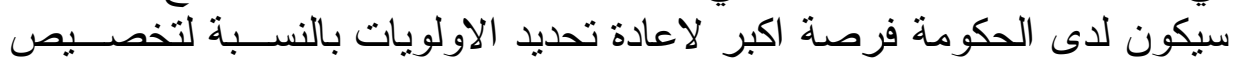
مو اردها البشرية و الخدمات الاجتماعية فردية.

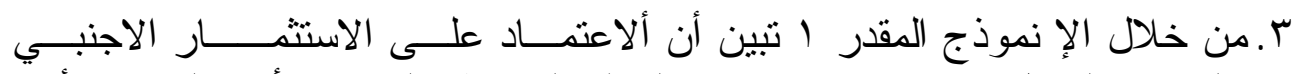

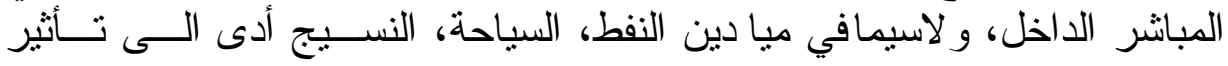

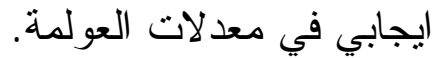

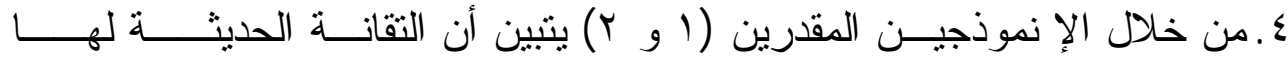

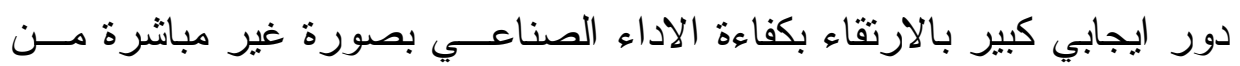

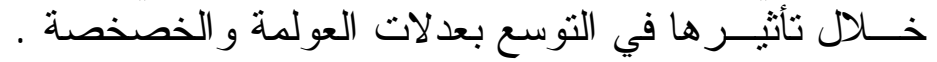

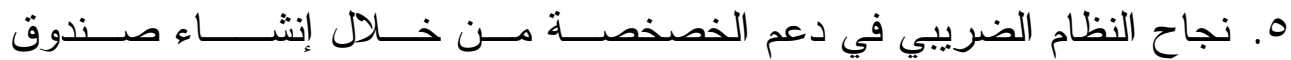

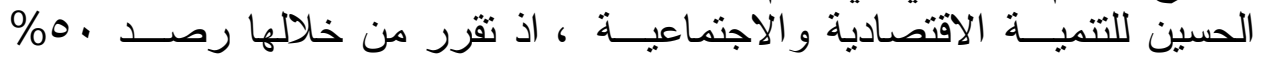

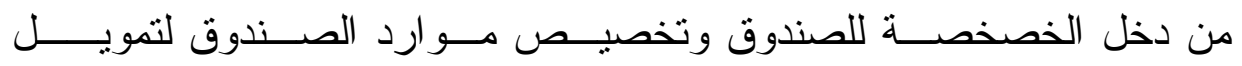

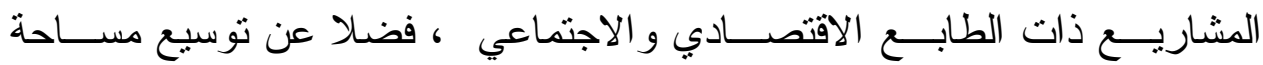
الخصخصة ومن ثم انعكاسها على الارتقاء بكفاءة الاداء الأهاء الصناعي.

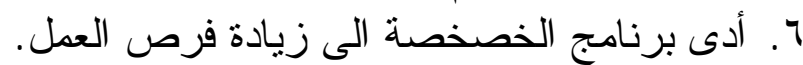

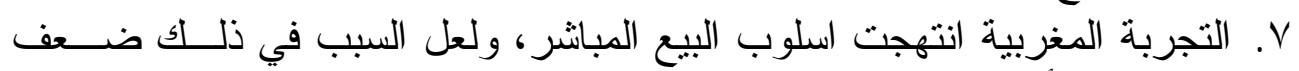

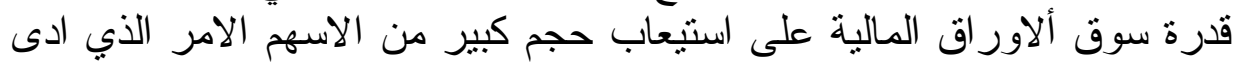

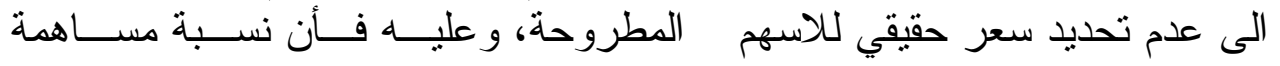
العاملين في المشروعات التي جرى هـ خصخصنتها تعد متو اضعة.

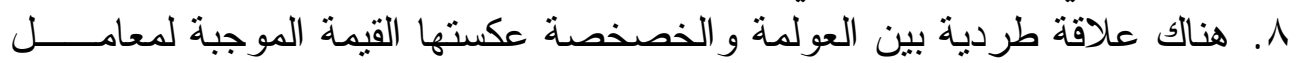

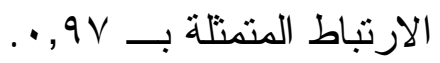

$$
\text { ثانياً - التوصيات }
$$

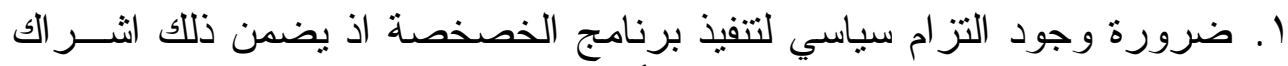

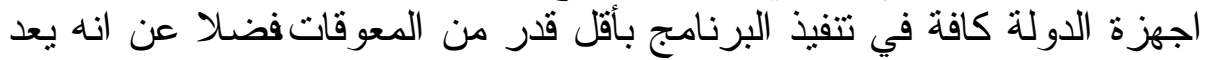
دافعاً هامأ لجذب الاستثمار ات وطمأنة المستثمريين المحليين و الاجانب.

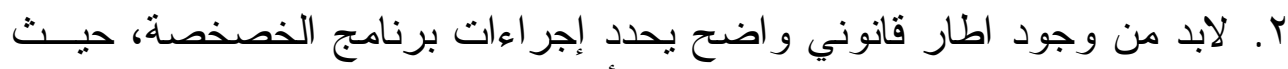

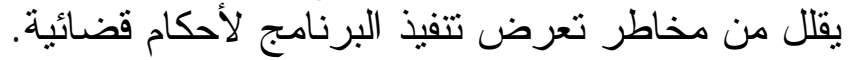

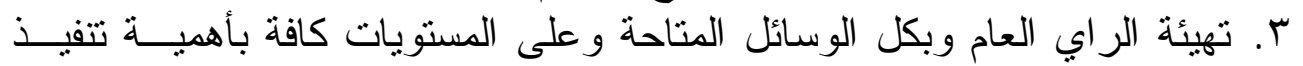

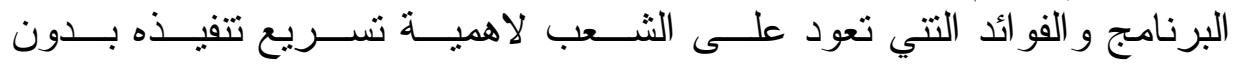

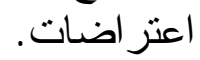
ع. التأكيد على مبادىء الثفافية و العلانية وتتفيذها بكل دقة دن قبل القائمين علـى كلى البرنامج في مر احله كافة . 
0. يجنيألضمن برنامج الخصخصة عدم الاضر ار بمصالح العاملين و لاســيما

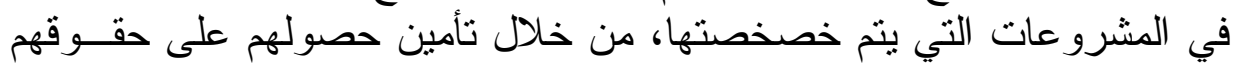

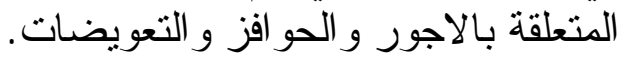

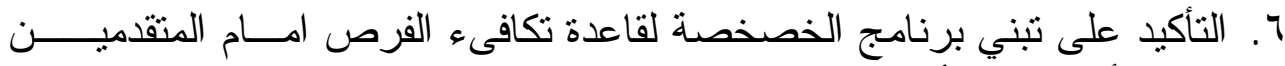

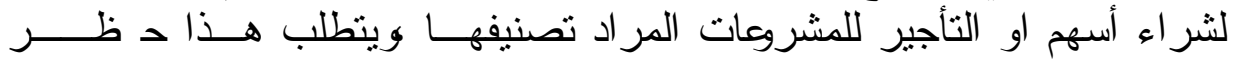

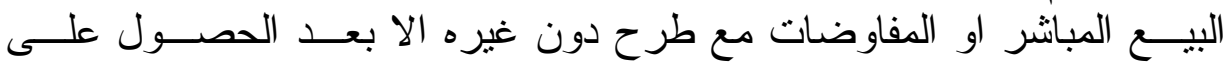

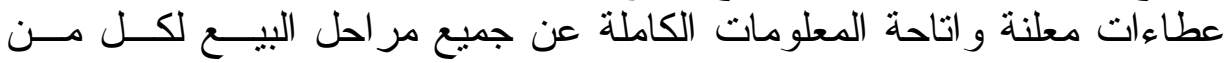
يرغب في الحصول عليها.

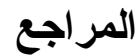 \\ اولاً - المر اجع باللغة العربية}

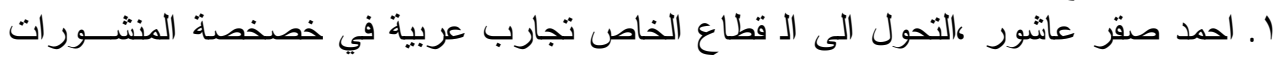

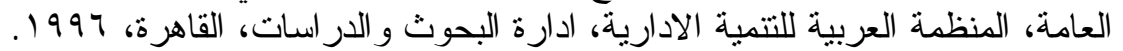

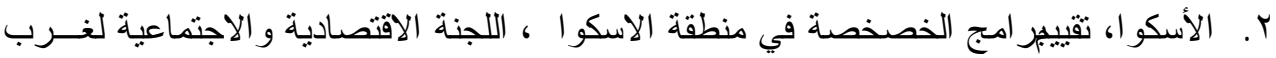

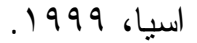

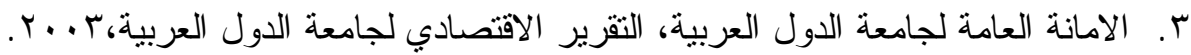

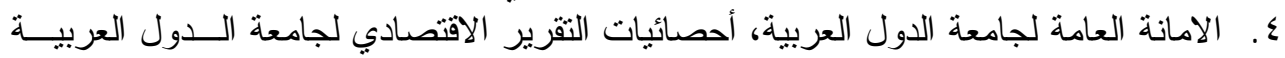

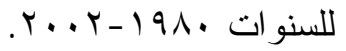

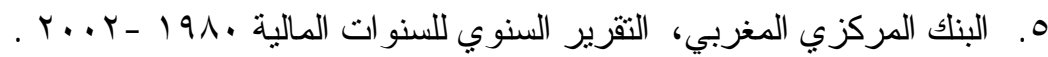

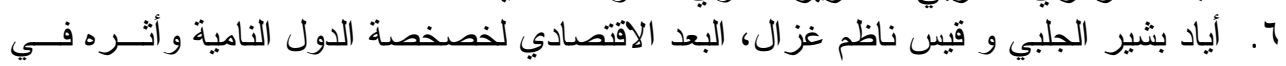

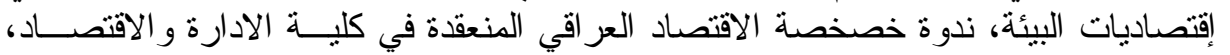

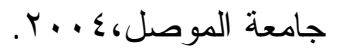
V. . رمضان الثر اح، الخصخصة ودور القطاع العام في مسيرة التتمية في دولة الكويت، مجلـــة

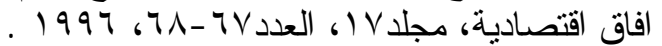

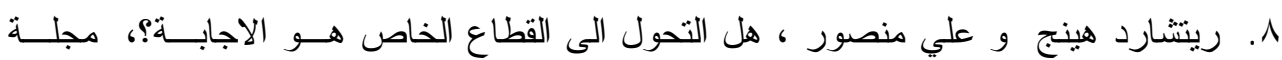

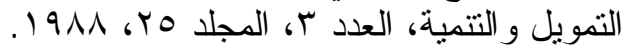

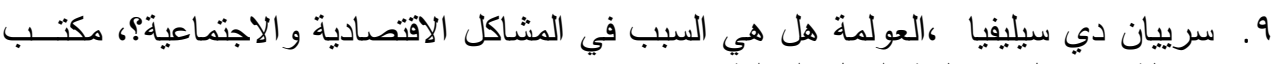

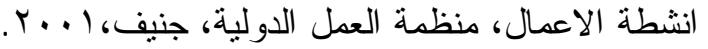

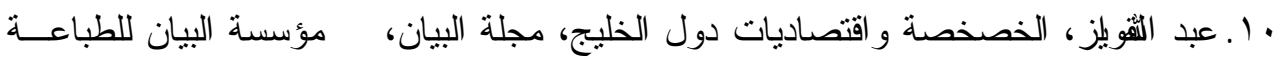

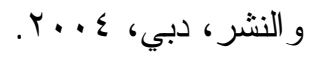

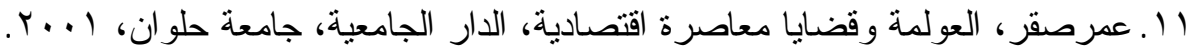

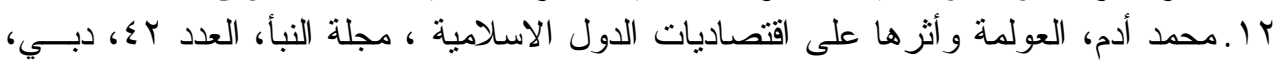
.r...

\section{ثانيا - المر اجع باللغة الاجنبية}

1. Ahmed M. Jiyad, The Social Balance Sheet of Privatization in Arab Countries The Third Nordic Conference on Middle Eastern Studies: www.Hf.Uibndin,1995

2. Boud Man, Anthony Evining, Owener Ship and Per Formancein, 1989 
3. Coskuncanm Aktan, Desumbe, An introduction to the Theory of Privatization. Dokuzeylul University Turkey, The Journal of Social Political and Economic Studies volum 20 ,Number 2,1995 .

4. Hood Nnds, The Economic of Multinational Enterprise Esse, U.K: Longman Group Ltd, 1981.

5. Karla Brom, Issues of Post Privatization Corporate Governance, Published by The Orgniztion for Economic Operation and Development (OECD). www.Oecd. Orgisgel, 1995

6. Sheshin Ski and Luis Eellpe, Briefing Note For Consulting Assistance on Economic Reform Discussion Paper No. 35, Privatization and its Benefit, 1995. 